\title{
Invasion of Phytophthora infestans at the Landscape Level: How Do Spatial Scale and Weather Modulate the Consequences of Spatial Heterogeneity in Host Resistance?
}

\author{
Peter Skelsey, Walter A. H. Rossing, Geert J. T. Kessel, and Wopke van der Werf
}

First and fourth authors: Wageningen University, Department of Plant Sciences, Crop and Weed Ecology Group, P.O. Box 430, 6700 AK Wageningen, The Netherlands; second author: Wageningen University, Department of Plant Sciences, Biological Farming Systems Group, P.O. Box 563, 6708 PB Wageningen, The Netherlands; and third author: Plant Research International, P.O. Box 16, 6700 AA Wageningen, The Netherlands.

Accepted for publication 4 June 2010.

\begin{abstract}
Skelsey, P., Rossing, W. A. H., Kessel, G. J. T., and van der Werf, W. 2010. Invasion of Phytophthora infestans at the landscape level: How do spatial scale and weather modulate the consequences of spatial heterogeneity in host resistance? Phytopathology 100:1146-1161.

Strategic spatial patterning of crop species and cultivars could make agricultural landscapes less vulnerable to plant disease epidemics, but experimentation to explore effective disease-suppressive landscape designs is problematic. Here, we present a realistic, multiscale, spatiotemporal, integrodifference equation model of potato late blight epidemics to determine the relationship between spatial heterogeneity and disease spread, and determine the effectiveness of mixing resistant and susceptible cultivars at different spatial scales under the influence of weather. The model framework comprised a landscape generator, a potato late blight model that includes host and pathogen life cycles and fungicide management at the field scale, and an atmospheric dispersion model that calculates spore dispersal at the landscape scale. Landscapes consisted of one or two distinct potato-growing regions (6.4-by-6.4-km) embedded within a nonhost matrix. The characteristics of fields and growing regions and the separation distance between two growing regions were investigated for their effects on disease incidence, measured as the

reduced the acreage of potato or increased the proportion of a resistant potato cultivar. Clustering potato cultivation in some parts of a region, either by planting in large fields or clustering small fields, enhanced the spread within such a cluster while it delayed spread from one cluster to another; however, the net effect of clustering was an increase in disease at the landscape scale. The planting of mixtures of a resistant and susceptible cultivar was a consistently effective option for creating potatogrowing regions that suppressed disease spread. It was more effective to mix susceptible and resistant cultivars within fields than plant some fields entirely with a susceptible cultivar and other fields with a resistant cultivar, at the same ratio of susceptible to resistant potato plants at the landscape level. Separation distances of at least $16 \mathrm{~km}$ were needed to completely prevent epidemic spread from one potato-growing region to another. Effects of spatial placement of resistant and susceptible potato cultivars depended strongly on meteorological conditions, indicating that landscape connectivity for the spread of plant disease depends on the particular coincidence between direction of spread, location of fields, distance between the fields, and survival of the spores depending on the weather. Therefore, in the simulation of (airborne) pathogen invasions, it is important to consider the large variability of atmospheric dispersion conditions.
\end{abstract} proportion of fields with $\geq 1 \%$ severity, after inoculation of a single potato grid cell with a low initial level of disease. The most effective spatial strategies for suppressing disease spread in a region were those that
Additional keywords: Gaussian plume model.
Host resistance is almost unanimously viewed as the most costeffective and sustainable form of plant disease management; however, counteractive to this form of management are a number of societal, economic, and market forces that determine what is grown and where (48). There is hope that genetic engineering technologies will yield improved variants of currently used crop cultivars that show far greater levels of resistance (15). However, pathogen populations will continue to evolve and respond to the new forms of genetic resistance that are deployed through genetic engineering; therefore, breakthrough of engineered resistance may only be a matter of time (26). It is then of paramount importance to understand how spatial deployment of resistant cultivars can mitigate the spread of newly virulent pathogen genotypes.

Biocides can provide effective protection but their applicability can be compromised by adverse health and environmental effects, the emergence of resistant pathogen strains, and faltering public

Corresponding author: P. Skelsey; E-mail address: pskelsey@k-state.edu

doi:10.1094/PHYTO-06-09-0148

(c) 2010 The American Phytopathological Society support for their frequent use in agriculture, especially in the Western world. Nonetheless, the efficacy of biocides is appealing to farmers in developed and developing economies alike, and their use is a common practice throughout the world $(10,17,25)$.

Phytophthora infestans is a plant pathogen that has shaped nations. In Europe in the mid-nineteenth century, potato late blight (caused by $P$. infestans) spread like wildfire. Crop losses were most severe in Ireland, where the "potato famine" resulted in the death of 1 million people and the displacement of 1.5 million more $(23,53) . P$. infestans has been the subject of much academic interest ever since but it continues to be a problem in potatogrowing practice. Currently, $P$. infestans is responsible for multibillion dollar losses annually in global potato and tomato production (4). P. infestans is notorious for rapidly developing resistance to host defense (11). This aptitude for developing resistance has been linked to the localization of virulence genes on rapidly evolving regions in the $P$. infestans genome (14).

The aerial spread of pathogen inoculum to uninfected hosts is crucial to the epidemic phase of potato late blight $(18,19,46)$. Thus, epidemic development is a spatial process; or, more specifically, a combination of spatial processes with length scales 
ranging from a few millimeters to several kilometers or more. Host encounter by dispersing spores is highly dependent on meteorological conditions and the spatial characteristics of crops and landscapes. Variation in meteorological driving forces and heterogeneity in the structure of host populations are therefore of fundamental importance to the epidemic process. The paucity of quantitative data concerning spatial aspects of the disease cycle beyond the field scale is due to the difficulty of conducting experiments at large spatial scales, beyond the plot, and to the difficulty of unraveling the complex interplay between meteorological and spatial variables. Due to lack of knowledge at large spatial scales, the potential landscape dimension of potato late blight epidemics has been scarcely incorporated into integrated crop protection strategies. It is possible that knowledge of the spatial epidemiology of the pathogen could be used to improve local and regional management of the disease and reduce the need for fungicides.

The efficacy of spatial disease management strategies is likely to depend on the scale of pathogen dispersal relative to the scale of (induced) heterogeneities in host populations. Detached $P$. infestans sporangia are killed within $1 \mathrm{~h}$ on sunny days but many survive for several hours on cloudy days $(27,44)$. Given that wind speeds can vary greatly during spore transport (e.g., 1 to $20 \mathrm{~m} \mathrm{~s}^{-1}$ ), a wide range of dispersal distances must be considered possible. Zwankhuizen et al. (54), using DNA fingerprinting, showed that $P$. infestans spread from infested crops over an area of $25 \mathrm{~km}^{2}$ in a period of 2 weeks. In one instance, sporangia of $P$. infestans from a refuse pile were found or inferred to infect potato fields up to $900 \mathrm{~m}$ away. The capacity for long-distance dispersal gives a mixed review on the likelihood that spatial strategies for placement of potato crops and potato cultivars will be effective in controlling the regional spread of potato late blight. Moreover, very little quantitative information exists with which to develop such strategies. Nevertheless, farmers and policy makers are interested in making potato cultivation more robust to disease through the development of disease-buffering landscapes.

Evidence of the beneficial effects of host diversity on the spread of potato late blight have been found in field studies $(1,12)$, and the effectiveness of cultivar mixtures in some pathosystems, e.g., rice blast $(24,28,36,51,55)$, is well established. We are unaware, however, of any information about the role that spatial resistance deployment strategies may play in potato late blight management at a regional scale. Does spatial heterogeneity at a landscape scale matter for disease spread and, if so, is spatially strategic management of potato cultivars at a landscape scale more or less effective than using cultivar mixtures within fields?

To address this question, we developed a quantitative, processbased modeling framework. Given that spatial increase of potato late blight is the product of a complex interplay between meteorological driving forces, management practices, and the spatial characteristics of crops and landscapes, we included potentially relevant detail in these elements in our analyses. The simulation framework described below comprises a landscape generator; a validated, parsimonious field-scale potato late blight model; and a parsimonious long-range atmospheric spore dispersion model for the spread of spores at landscape scale. The potato late blight model includes host and pathogen life cycles, fungicide management (both protectant and eradicant treatments), and weatherdependent relations for key disease cycle processes. The model framework is based on components described and tested in earlier work (39-41), but adapted to enable upscaling to the landscape level.

As field-to-field spread of disease is considered, the method used to model inoculum dispersal is particularly important. Many epidemiological studies choose negative exponential and power law dispersal functions for their mathematical simplicity (30). However, such descriptive mathematical models do not account for the effects of variable weather conditions on the long-distance spread of spores and the survival of spores as affected by the duration of transport through the air. Here, we choose an atmospheric dispersion model in order to capture the variability of dispersal in time and space due to the variability of weather. The atmospheric dispersion model developed and tested here (for the transport of botanical particles) is a simplified version of more elaborate models documented in Skelsey et al. $(37,38)$.

Our aim is to quantify the effect of spatial heterogeneity at different spatial scales on the spread of potato late blight, taking into account realistic yet parsimonious models of disease spread and atmospheric spore transport in combination with observed weather data. Weather determines the formation, release, and escape of spores from the canopy, the direction and extent of spore dispersal, the survival and deposition of spores, and the ability of spores to infect. Thus, weather affects the whole chain of events that spores go through to cause infections somewhere in the landscape after arriving from another place. Because weather has the potential to modify the effects of landscape design on disease invasion, we ask: what is the contribution of weather conditions on the magnitude of host diversity and landscape design effects?

\section{THEORY AND APPROACHES}

Spatial scales. Here, we use the word "region" in a strict way as a 6.4-by-6.4-km area with potato cultivation in one or more fields. The word "landscape" is used more broadly as any assembly of potato and nonpotato fields. A "cluster" is defined as a spatially contiguous set of potato fields within a region. "Host diversity" refers to the genetic composition of host populations.

We consider three spatial scales when studying the effects of host diversity in potato populations on epidemics of $P$. infestans: within fields, between fields within regions, and between regions in a larger landscape setting. Thus, the host population can be diverse at three spatial scales: within fields, between fields, and between regions. Within-field host diversity concerns the use of cultivar mixtures (34). Between-field host diversity means that different fields in a region may have a different cultivar. We pragmatically distinguish two phenotypes: resistant and susceptible. At the regional level (one-region scenarios), epidemics are simulated under a variety of landscape configurations concerning the proportion of potato plants, the proportion of potato plants that are susceptible and resistant to $P$. infestans, size and shape of fields, and the spatial clustering of fields. Studies within regions are conducted both with cultivar mixtures (within-field mixing) and with homogeneous fields (between-field mixing). We also assess management options at larger spatial scales using scenarios that vary the separation distance between two growing regions (two-region scenarios). In the two-region scenarios, three spatial scales of host diversity are simulated: within field, between field, and between region, whereby each region is homogeneous for a particular potato cultivar.

Simulation framework. An adaptation of a spatiotemporal/ integrodifference equation model of the potato late blight pathosystem originally developed by Skelsey et al. (41) is used to simulate disease dynamics at the level of grid cells ( 1 ha), where a grid cell may represent a part or the whole of one potato field. This model was validated using data from field trials on the temporal development of two genotypes of $P$. infestans in five potato cultivars in the Netherlands (39). Individual grid cells in the landscape are linked through models describing spore dispersal and survival. Multiple growing seasons are simulated on each landscape. Within this modeling framework, the composition, configuration, and connectivity of potato populations are manipulated in order to study their influence on disease spread.

A schematic overview of the framework is given in Figure 1. A broad description of the simulation framework and scenario studies are provided in the following sections. Details of the 
models and solution methods are given in the Appendix and a summary of symbol definitions and units is provided in Table 1.

Weather data. Hourly weather data were provided by the Wageningen University "Haarweg" weather station (http://www. maq.wur.nl), $51^{\circ} 58^{\prime} \mathrm{N}, 5^{\circ} 38^{\prime} \mathrm{E}$. The growing season is assumed to last from 1 May to 30 September, and a total of 10 years of weather data were used (1997 to 2006).

Landscape generation. Neutral landscapes (not shaped by biotic or abiotic processes) are generated on two-dimensional grids. In the one-region scenarios, landscapes contain a single potatogrowing region (6.4-by-6.4-km) surrounded by a buffer of "empty space" to facilitate spore loss from the region and represent a potato-growing area that is embedded in a greater landscape

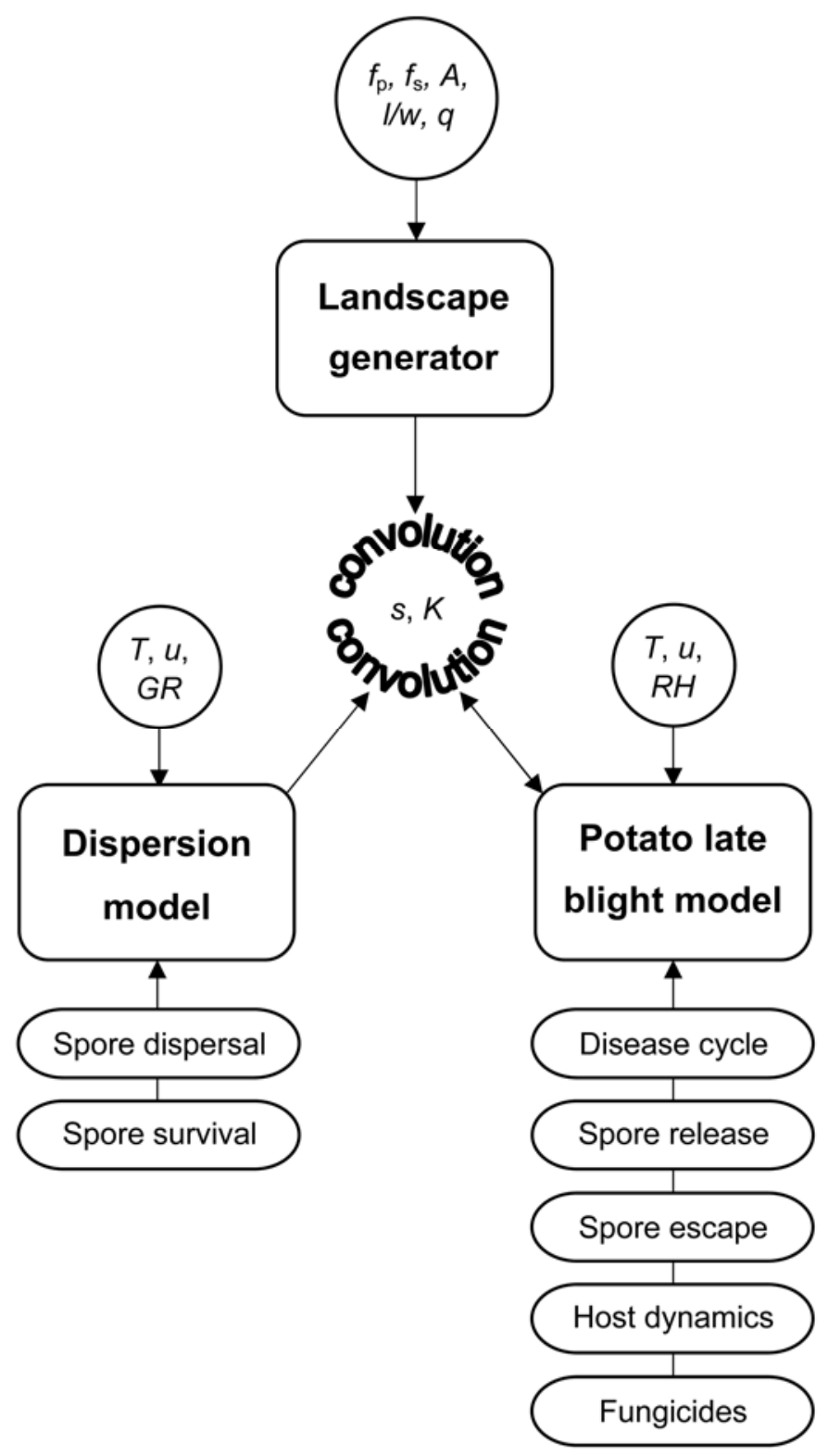

Fig. 1. Schematic overview of the simulation framework. Large boxes show main model components. Smaller boxes show submodels. Circles show input variables: $f_{\mathrm{p}}=$ fraction of the landscape that is potato; $f_{\mathrm{s}}=$ fraction of the potato population that is susceptible, $A=$ field area $\left(\mathrm{m}^{2}\right) ; l / w=$ length/width ratio of fields; $q=$ host connectivity, a measure of clustering (equation A12); $T=$ temperature $\left({ }^{\circ} \mathrm{C}\right)$ measured at two heights $(0.1$ and $1.5 \mathrm{~m}) ; u=$ wind speed $\left(\mathrm{m} \mathrm{s}^{-1}\right)$ measured at $10 \mathrm{~m}$, and wind direction; $G R=$ global radiation $\left(\mathrm{W} \mathrm{m}^{-2}\right)$; $R H=$ relative humidity (\%); $s=$ spores (no.), a spatial distribution of (escaped) sporangia; and $K=$ dispersal kernel $\left(\right.$ no. $\mathrm{m}^{-2}$ ), a spatial distribution of viable spore deposition flux values that is used as a contact distribution. The "convolution" symbol indicates a spatial convolution, which is performed using fast Fourier transformations. without potato plants to which spores may be lost. In the tworegion scenarios, landscapes contain two such 6.4-by-6.4-km regions with a variable amount of nonpotato area between them. The whole system of two regions and the separating space is again embedded in a larger matrix without potato plants in order to facilitate spore loss from the system. Landscapes are subdivided into 100-by-100-m grid cells and individual plants are not simulated. The motivation for the extent $(6.4-\mathrm{by}-6.4-\mathrm{km})$ and subdivision of the simulated landscapes was primarily pragmatic. The fast Fourier transform algorithm used to solve spatial phenomena in the model is more efficient when the dimensions of input numerical arrays are a power of 2 (see Appendix). Larger gridded landscapes than used here greatly increased the execution time of the model and became limiting to the number of simulations that could be performed.

Within a growing region, the number, size, shape, aggregation, and classification (susceptible, resistant, or a cultivar mixture) of potato fields is varied. Potato fields are simulated either as single grid cells (100-by-100-m) or as assemblies of grid cells if larger fields or fields of a different shape are required. Different levels of clustering of 100-by-100-m potato fields are created from an initial random allocation of potato cells within a region. Potato cells with the lowest adjacency score, as judged by the number of potato neighbors, are swapped with nonpotato cells with the highest number of potato neighbors until a predetermined level of connectivity is achieved. Adjacency is assessed using the "queen's adjacency" system (cells that share a border, including cells on the diagonal). Connectivity is assessed using a host connectivity parameter, $q$ (Appendix) (41).

In all landscapes, two potato cultivars are represented: susceptible and resistant. Resistant cultivars can become infected but key life cycle parameters such as infection efficiency, lesion growth rate, and sporulation intensity are far reduced compared with the susceptible cultivar (Table 2). Parameters defining the susceptible and resistant cultivars are described in the Appendix.

One-region scenarios with cultivar mixtures. To identify the spatial parameters that have the greatest influence on the rate and extent of disease invasion within an individual growing region, five sets of scenarios were defined. These scenario sets address the influence of (i) the proportion of potato in the landscape; (ii) the proportion of the potato population that is susceptible to disease, the remainder being resistant; (iii) the size of fields; (iv) the shape of fields (elongation in a north-south direction, perpendicular to the westerly wind directions that are prevalent in the weather data sets); and (v) the degree of spatial clustering of potato fields. The range of parameter settings for each of the five sets of scenarios is specified in Table 3. Landscape designs resulting from the range of parameter settings in each of the five basic scenario sets are depicted in Figure 2.

One-region scenarios with heterogeneous fields. Here, the same scenarios were studied as in the one-region scenarios with homogeneous fields, with one difference: susceptible and resistant potato cultivars were mixed within fields, and all fields in a region are, in this respect, identical. Because individual plants were not simulated, field-scale cultivar mixtures were approximated by weighting the resistance components-infection efficiency (IE), radial lesion growth rate $(L G)$, and sporulation intensity per unit of infectious tissue $(S I)$ - with $f_{\mathrm{s}}$, the fraction of the potato population classified as susceptible:

$$
\lambda_{\mathrm{m}}=\lambda_{\mathrm{s}} f_{\mathrm{s}}+\lambda_{\mathrm{r}}\left(1-f_{\mathrm{s}}\right)
$$

where $\lambda$ represents one of the three cultivar-specific resistance components (Table 2) and subscripts $\mathrm{m}, \mathrm{s}$, and $\mathrm{r}$ stand for mixture, susceptible, and resistant, respectively. The scenarios employing genotypic diversity of potato cultivars at different spatial scales of mixing result in essentially the same maps as those represented in Figure 2 (i.e., only the [genotypic] composition of fields and regions change). 
Two-region scenarios. The use of regional separation of potato cultivation as a barrier to pathogen invasion was investigated at larger spatial scales. The two-region scenario set addressed the influence of the separation distance between two growing regions on epidemic extent. Two regions were simulated: a "donor" region (initially infected) and a "receptor" region (initially diseasefree). In each two-region scenario, one-fourth of the fields in both regions are planted with potato. Different potato cultivars can be deployed at three spatial scales of cultivar mixing: (i) between fields, (ii) within fields, and (iii) between regions. In the first, each field is planted with either a susceptible or a resistant cultivar. In the second, each field is planted with a 50:50 mixture of resistant and susceptible potato cultivars. In the third, all potato fields in the donor area are planted with a susceptible potato cultivar while those in the receptor area are planted with a resistant cultivar. In the two-region scenarios, both regions are placed along a west-east axis, with the donor region west and the receptor region east (i.e., in line with prevailing westerly winds in the weather data set).

A single source of primary inoculum was simulated in all model runs; a single susceptible or mixed cultivar potato parcel of 1 ha was randomly selected. Epidemics were then initiated with 10 lesions $\mathrm{m}^{-2}$ of ground area in the selected grid cell, and allowed to progress for the full length of each growing season (1 May to 30 September). The severity of the epidemic was characterized by the final proportion of potato grid cells (100-by$100-m$ ) with $\geq 1 \%$ severity (latent + infectious + necrotic leaf area). This variable was found in pilot studies to be a good indicator of the speed and extent of invasions.

Effects of weather and landscape variability. In all, 10 random landscapes were generated for each scenario and, on each of these, 10 different growing seasons, represented by differ-

TABLE 1. Symbols used in this study

\begin{tabular}{|c|c|c|}
\hline Symbol & Units $^{\mathrm{a}}$ & Description \\
\hline$A$ & $\left(\mathrm{~m}^{-2}\right)$ & Area \\
\hline $\bar{c}$ & $\left(\right.$ no. $\left.\mathrm{m}^{-3}\right)$ & Aerial spore concentration \\
\hline $\bar{c}_{0}$ & $\left(\right.$ no. $\mathrm{m}^{-3}$ ) & Concentration of spores at the surface \\
\hline$D$ & $\ldots$ & Modified index of agreement \\
\hline$F_{\mathrm{d}}$ & $\left(\right.$ no. $\left.\mathrm{m}^{-2}\right)$ & Dry deposition flux \\
\hline$f_{\mathrm{e}}$ & $\ldots$ & Fraction of spores that escape the canopy \\
\hline$f_{\mathrm{p}}$ & $\ldots$ & Fraction of potato \\
\hline$f_{\mathrm{r}}$ & $\ldots$ & Fraction of spores released from sporangiophores \\
\hline$f_{\mathrm{s}}$ & $\ldots$ & Fraction of potato acreage that is susceptible \\
\hline$f_{\mathrm{v}}$ & $\ldots$ & Fraction of spores that remain viable after transport \\
\hline$G R$ & $\left(\mathrm{~W} \mathrm{~m}^{-2}\right)$ & Global radiation (shortwave direct-plus diffuse) \\
\hline$H$ & $\ldots$ & Heaviside function \\
\hline$h$ & $(\mathrm{~m})$ & Effective height of the source (canopy height - displacement height) \\
\hline$I E$ & $\ldots$ & Infection efficiency \\
\hline$I P$ & (days) & Infectious period \\
\hline$K$ & $\left(\right.$ no. $\left.\mathrm{m}^{-2}\right)$ & Viable spore deposition kernel \\
\hline $\bar{K}$ & $\left(\right.$ no. $\left.\mathrm{m}^{-2}\right)$ & Average dispersal kernel \\
\hline$L$ & $(\mathrm{~m})$ & Monin-Obukhov length scale \\
\hline$l / w$ & $\ldots$ & Length to width ratio \\
\hline$L A I$ & $\ldots$ & Leaf area index \\
\hline$L G$ & $\left(\mathrm{~m}\right.$ day $\left.^{-1}\right)$ & Radial lesion growth rate \\
\hline$L P$ & (days) & Latent period \\
\hline $\mathrm{N}$ & $\ldots$ & Number of observations \\
\hline$O$ & $\left(\right.$ no. $\left.\mathrm{m}^{-3}\right)$ & Observed spore concentration \\
\hline$P$ & $\left(\right.$ no. $\mathrm{m}^{-3}$ ) & Predicted spore concentration \\
\hline$Q$ & $\left(\right.$ no. $\left.\mathrm{s}^{-1}\right)$ & Source strength \\
\hline$q$ & $\ldots$ & Host connectivity (equation A12) \\
\hline$R H$ & $(\%)$ & Relative humidity \\
\hline$r_{\mathrm{d}}$ & $\left({ }^{\circ} \mathrm{C}-\mathrm{day}^{-1}\right)$ & Relative death rate of host \\
\hline$r_{\mathrm{g}}$ & $\left({ }^{\circ} \mathrm{C}-\mathrm{day}^{-1}\right)$ & Relative growth rate of host \\
\hline SI & $\left(\right.$ no. $\left.\mathrm{m}^{-2}\right)$ & Sporulation intensity \\
\hline$s$ & (no.) & Spores \\
\hline$T$ & $\left({ }^{\circ} \mathrm{K}\right)$ & Temperature \\
\hline$T_{\mathrm{L}}$ & (s) & Lagrangian time scale \\
\hline$t$ & (s) & Time \\
\hline$u$ & $\left(\mathrm{~m} \mathrm{~s}^{-1}\right)$ & Wind speed \\
\hline $\bar{u}$ & $\left(\mathrm{~m} \mathrm{~s}^{-1}\right)$ & Mean wind speed at effective source height, $h$ \\
\hline$v_{\mathrm{d}}$ & $\left(\mathrm{m} \mathrm{s}^{-1}\right)$ & Deposition velocity \\
\hline$v_{\mathrm{s}}$ & $\left(\mathrm{m} \mathrm{s}^{-1}\right)$ & Stokes settling velocity \\
\hline$x$ & $(\mathrm{~m})$ & Coordinate \\
\hline$x_{\mathrm{G}}$ & $(\mathrm{m})$ & Distance at which a streamline from the image source cuts through the ground plane \\
\hline$y$ & $(\mathrm{~m})$ & Coordinate \\
\hline$z$ & $(\mathrm{~m})$ & Coordinate \\
\hline$\alpha$ & $\ldots$ & Reflection coefficient \\
\hline$\varphi$ & $\left(\mathrm{MJ} \mathrm{m}^{-2}\right)$ & Dose of global radiation (direct-plus diffuse shortwave radiation) received during transport \\
\hline$\kappa$ & $\ldots$ & von Kármán constant $(0.41)$ \\
\hline$\lambda$ & $\ldots$ & Cultivar-specific resistance component \\
\hline$\pi$ & $\ldots$ & Mathematical constant (3.14) \\
\hline$\rho$ & $\ldots$ & Factor of (artificially induced) predictive error \\
\hline$\sigma_{\mathrm{v}}$ & $\left(\mathrm{m} \mathrm{s}^{-1}\right)$ & Standard deviation of horizontal wind velocity fluctuations \\
\hline$\sigma_{\mathrm{w}}$ & $\left(\mathrm{m} \mathrm{s}^{-1}\right)$ & Standard deviation of vertical wind velocity fluctuations \\
\hline$\sigma_{\mathrm{y}}$ & $(\mathrm{m})$ & Standard deviation of the crosswind concentration distribution \\
\hline$\sigma_{\mathrm{z}}$ & $(\mathrm{m})$ & Standard deviation of the vertical concentration distribution \\
\hline$\tau$ & $(\mathrm{s})$ & Travel time \\
\hline
\end{tabular}

a ... Signifies that the defined quantity is dimensionless. 
ent weather data sets, were simulated. Incidence values were averaged over the 100 landscape and weather iterations per scenario. In the two-region scenarios, incidence was calculated in the receptor region only and also for the landscape as a whole.

Uncertainty analysis. Relative standard errors of incidence (standard error expressed as a percentage of the mean incidence) were calculated between years within random landscape iterations (replications) for each scenario. These describe year-to-year variability in disease for the same random landscape and, thus, indicate the influence of yearly variation in weather on disease invasion. Relative standard errors were also calculated between landscapes over 10 years of weather data per landscape, in order to assess the degree to which the precision of simulation results are affected by variability in the random maps.

Perturbation analysis. The robustness of simulation results was investigated by means of a coarse perturbation analysis. A magnifying or minimizing perturbation was applied to the rate of lesion formation by multiplying the number of new lesions formed in each grid cell at each time step by an arbitrary constant, $\rho(0.2,1$, or 5$)$. Interpretation focuses on the effects of these perturbations on emergent model trends (i.e., qualitative as opposed to quantitative effects). By proceeding in this manner, emergent trends in the effects of spatial design on the rate and spatial extent of epidemics can be checked against consistent over- or underprediction in model components.

\section{RESULTS}

Disease dynamics in 6.4-by-6.4-km regions with homogeneous fields. Potato fraction. Disease incidence increased by a factor 3.5 if the proportion of potato was increased from 1/64 to 1 (Fig. 3A). This result highlights the inherent vulnerability resulting from growing potato in concentrated growing regions.

Susceptible fraction. Increasing the susceptible fraction of potato plants from $1 / 64$ to 1 increased incidence by a factor of

TABLE 2. Parameters for the model potato cultivars distinguished in the study

\begin{tabular}{lcc}
\hline Parameter $^{\mathrm{a}}$ & Susceptible & Resistant \\
\hline Date of emergence & 1 May & 1 May \\
Date of harvest & 30 September & 30 September \\
Onset of leaf shedding $\left({ }^{\circ} \mathrm{C}\right.$-day) & 1,000 & 1,000 \\
$L A I_{\text {max }}$ & 6 & 6 \\
$r_{\mathrm{g}}\left({ }^{\circ} \mathrm{C}-\right.$ day $\left.^{-1}\right)$ & 0.02 & 0.02 \\
$r_{\mathrm{d}}\left({ }^{\circ} \mathrm{C}-\right.$ day $\left.^{-1}\right)$ & 0.01 & 0.01 \\
$I E$ & 0.03 & 0.01 \\
$I P($ days $)$ & 1 & 1 \\
$L P($ days $)$ & 5 & 5 \\
$L G\left(\mathrm{~m} \mathrm{day}^{-1}\right)$ & 0.005 & 0.002 \\
$S I\left(\right.$ no. $\left.\mathrm{m}^{-2}\right)$ & $4.6 \times 10^{8}$ & $1.6 \times 10^{8}$ \\
\hline
\end{tabular}

${ }^{\mathrm{a}} L A I_{\max }=$ maximum leaf area index; $r_{\mathrm{g}}$ and $r_{\mathrm{d}}=$ relative growth and death rates, respectively, of host; and $I P$ and $L P=$ infectious and latent periods, respectively. Infection efficiency (IE), lesion growth rate $(L G)$, and sporulation intensity $(S I)$ were determined experimentally providing parameter values for the susceptible (cv. Bintje, isolate IPO82001) and (partially) resistant (cv. Agria, isolate IPO82001) interactions (39).
13.5 (Fig. 3B). Therefore, increased diversification of resistance genes within susceptible monoculture systems emerges as a highly effective spatial stragey for suppression of epidemics.

Field size. Increasing the separation distance between fields within regions by planting potato in fewer but larger fields did not limit pathogen spread (Fig. 3C). On the contrary; incidence increased by a factor of 1.5 with an increase in field size from 1 to 64 ha. Thus, the ease with which disease could spread within large fields outweighed any suppressive effects caused by increasing distances between those fields.

Field shape. Making fields long and narrow, with the long side perpendicular to the prevaling wind direction, slightly reduced pathogen spread (Fig. 3D). Incidence decreased by a factor of 1.4 over the range of length/width ratios simulated, from a value of 1 for completely square fields (800-by-800-m) to a value of 64 for long, thin strips of potato plants $(6,400-$ by- $100-m)$. This suggests that deployment of potato in longer, thinner fields, perpendicular to the prevailing wind direction, could be used to limit pathogen invasion in situations where the overall area of individual potato fields cannot be reduced.

Clustering of potato fields. Aggregation of fields into clusters did not limit disease spread (Fig. 3E). Incidence increased by a factor of 1.6 when the spatial pattern of potato fields was changed from purely random (Poisson) to highly aggregated. This result is very similar to that obtained in the scenarios on field size, even though, in the current scenario set, larger areas of potato production were composed of clusters of small (1 ha) resistant and susceptible fields. It appears that there was a negligible field-scale mixing effect within clusters of (smaller) potato fields in the current scenario set (i.e., spore loss by deposition onto neighboring resistant fields in the cluster had little effect on the spread of disease within and between the larger areas [clusters] of potato production).

Disease dynamics in 6.4-by-6.4-km regions with cultivar mixtures. Potato fraction. Incidence increased by a factor of 2.6 if potato fraction was increased from $1 / 64$ to 1 (Fig. 3A). In comparing the results for an increasing potato fraction for homogeneous fields and cultivar mixtures, incidence values decreased by a factor of 2.8 (averaged over all values of potato fraction) when cultivar mixtures were deployed. Thus, it was more effective to use cultivar mixtures within fields than between fields to suppress pathogen spread. However, planting cultivar mixtures did not nullify the adverse effect of planting more potato in a region.

Susceptible fraction. Increasing the susceptible fraction of the host population from 1/64 to 1 increased incidence by a factor of 33.4 (Fig. 3B). In comparing the between- and within-field cultivar-mixing schemes, incidence values decreased by a factor of 2.5 (averaged over all values of susceptible fraction) when cultivar mixtures were deployed.

Field size. Increasing the separation distance between fields with cultivar mixtures by planting potato in fewer but larger fields increased incidence. In line with results obtained with homogeneous fields, incidence was increased by a factor of 2.2 as field size was increased from 1 to 64 ha (Fig. 3C). Still, cultivar mixtures were more effective than homogeneous fields over the entire

TABLE 3. Parameter settings in the one-region scenarios ${ }^{\mathrm{a}}$

\begin{tabular}{|c|c|c|c|c|c|}
\hline $\begin{array}{l}\text { Scenario } \\
\text { study }\end{array}$ & Modified variable & Potato fraction & $\begin{array}{c}\text { Susceptible } \\
\text { potato fraction }\end{array}$ & Field dimensions $(100 \mathrm{~m})$ & Spatial pattern of fields \\
\hline 1 & Potato fraction & $1 / 64,1 / 16,1 / 4,1$ & $1 / 4$ & 1-by-1 & Random \\
\hline 2 & Susceptible potato fraction & $1 / 4$ & $1 / 64,1 / 16,1 / 4,1$ & 1-by-1 & Random \\
\hline 4 & Field shape & $1 / 4$ & $1 / 4$ & 8-by-8, 16-by-4, 32-by-2, 64-by-1 & Random \\
\hline 5 & Clustering of fields & $1 / 4$ & $1 / 4$ & 1-by-1 & Clustered $q=0.6,0.7,0.8,0.9^{b}$ \\
\hline
\end{tabular}

${ }^{\text {a }}$ Potato-growing regions are 6.4-by-6.4-km embedded within a larger area of nonhost space.

${ }^{\mathrm{b}}$ Host connectivity $(q)$ is defined using equation A12. 
range of field sizes; incidence was a factor of 2.8 lower (averaged over all field sizes) when cultivar mixtures were deployed compared with the use of homogeneous fields.

Field shape. Incidence decreased by a factor of 1.8 when length/width ratio was modifed from 1 to 64 while fields were planted with cultivar mixtures (Fig. 3D). Again, cultivar mixtures were more effective than homogeneous fields over the range of length/width ratios, and incidence values decreased by a factor of 2.4 (averaged over the full range of length/width ratios) when cultivar mixtures were deployed.
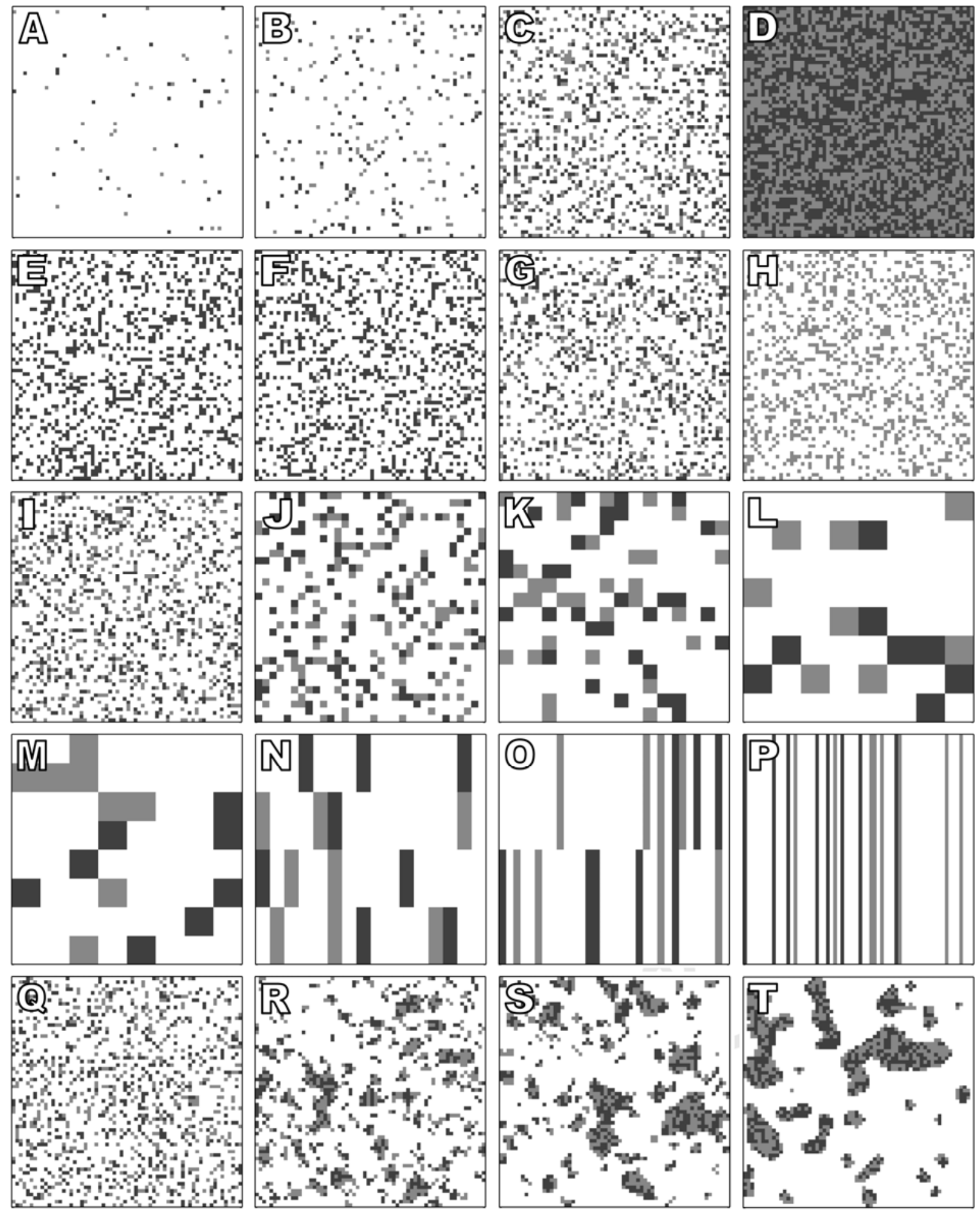

Fig. 2. Range of landscape designs for the parameter settings in the one-region scenarios (Table 3): (i) A to D, fraction of the landscape planted with potato increases from 1/64 to 1; (ii) $\mathbf{E}$ to $\mathbf{H}$, fraction of the potato population that is the susceptible phenotype increases from 1/64 to 1; (iii) $\mathbf{I}$ to $\mathbf{L}$, field size increases from 1 to 64 ha; (iv) $\mathbf{M}$ to $\mathbf{P}$, length/width ratio of field dimensions increases from 1 to 64 ; and (v) $\mathbf{Q}$ to $\mathbf{T}$, clustering of potato fields increases from 0.6 to 0.9 , where clustering is defined using the host connectivity parameter (equation A12). All simulated landscapes for the one-region scenarios are 6.4-by-6.4-km. Maps show landscape designs with homogenous fields (between-field cultivar-mixing scheme), where light-gray fields are the susceptible potato phenotype, dark-gray fields are the resistant potato phenotype, and white areas are nonhost to potato late blight. Landscape designs with heterogeneous fields (within-field cultivar mixing) are essentially similar, except that all fields contain a mixture of the two potato phenotypes. 
Clustering potato fields. This did not limit disease spread (Fig. $3 \mathrm{E})$. Incidence increased by a factor of 2.1 when the spatial pattern of potato fields was changed from purely random (Poisson) to highly aggregated when cultivar mixtures were deployed. In comparing the clustering scenarios for homogeneous fields and cultivar mixtures, incidence was a factor of 2.8 lower (averaged over all levels of clustering) when cultivar mixtures were deployed.

Overall, a comparison of one-region scenarios with homogeneous fields versus those with cultivar mixtures indicates that mixing within fields is a more effective option for slowing down the spread of epidemics.

Disease dynamics in two-region scenarios. Incidence of disease in the receptor region decreased markedly as distance from the source region was increased (Fig. 4). Incidence of disease in the receptor region was least when it consisted entirely of resistant potato cultivars, with all susceptible potato cultivars being grown in the source region; however, this came at the expense of a high disease incidence in the source region and in the two regions as a whole (Fig. 4C). Overall disease incidence in two regions was similar whether susceptible and resistant potato cultivars were grown in separate fields within regions (Fig. 4A) or in separate regions (Fig. 4C) but lowest overall disease incidence resulted when the resistant and susceptible cultivars were mixed within fields in every field in both regions (Fig. 4B). This result again points to the superior effect of mixing at small spatial scales.

The minimum separation distance required to completely prevent epidemic spread between regions depended on the scale at which resistant and susceptible cultivars were mixed. When cultivar mixtures were used within fields, the minimum separation distance was $32 \mathrm{~km}$ (Fig. 4B); when the source region was entirely susceptible and the receptor region entirely resistant, the minimum separation distance was $16 \mathrm{~km}$ (Fig. 4C); and when both regions contained susceptible and resistant potato cultivars, grown in homogeneous fields, the minimum distance (if any) was $>32 \mathrm{~km}$ (Fig. 4A).

Uncertainty analysis. For the one-region scenarios, relative standard errors between years and within random landscape iterations (describing the influence of variability in weather data on incidence) were 8 to $20 \%$ (across all parameter value manipulations and spatial scales of mixing of host cultivars), with a mean value of $12 \%$. Relative standard errors between landscapes within years (describing the influence of variation in landscapes on incidence) were 2 to $10 \%$, with a mean value of $6 \%$.

For the two-region scenarios, for incidence in the receptor region only, relative standard errors between years and within random landscape iterations were 0 to $71 \%$, with a mean value of $21 \%$ for the two-region scenarios. Relative standard errors between landscapes within years were 0 to $67 \%$, with a mean value of $10 \%$. This larger variation is explained as follows. Receptor regions were disease free at the beginning of each simulation; disease first had to spread from the donor region and then spread through the receptor region. Therefore, random variation in weather conditions and host locations affected incidence in the receptor region through its influence on both the betweenregion and within-region components of epidemic spread. As the
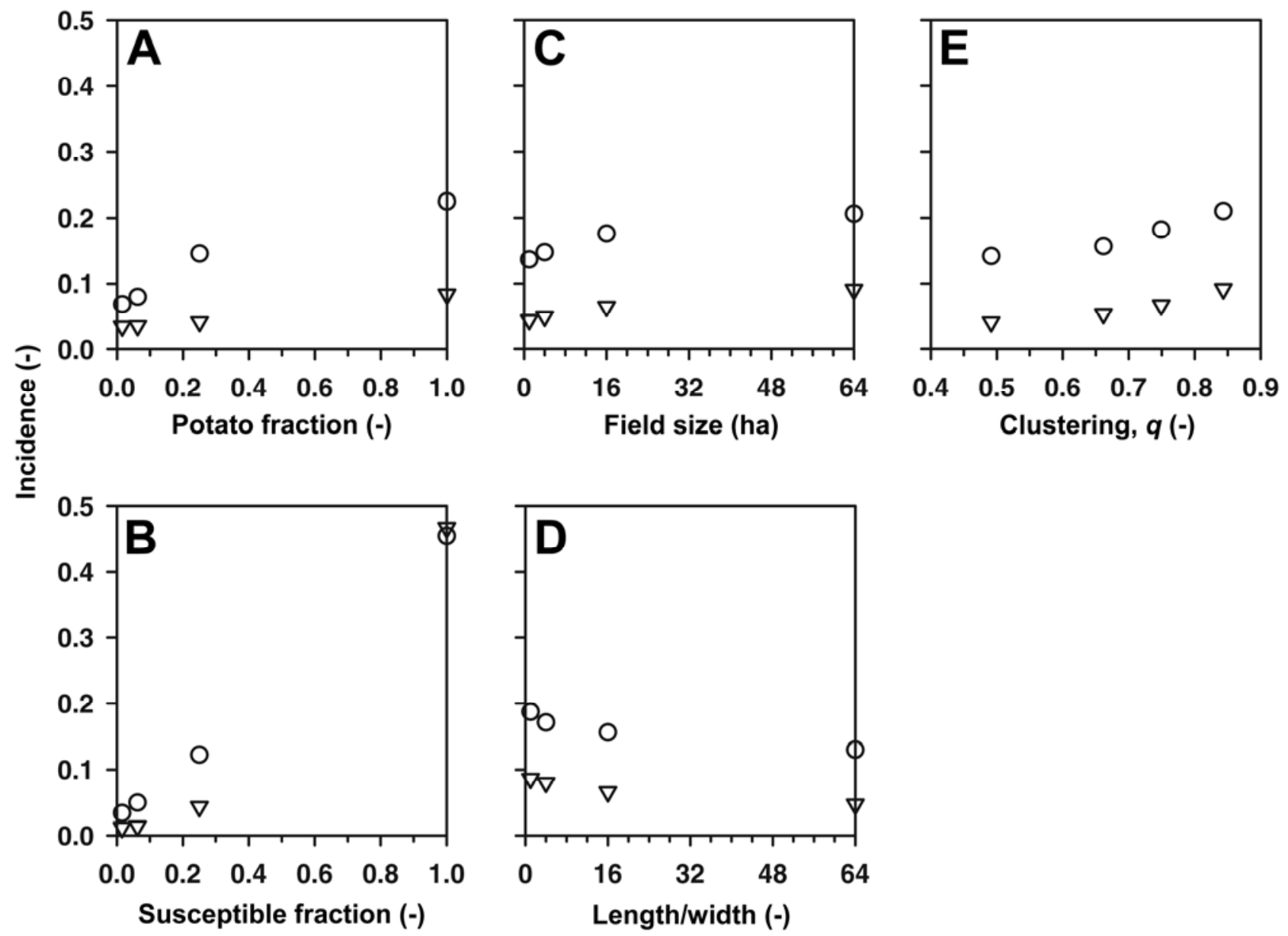

Fig. 3. Influence of spatial host population characteristics on the spatial extent of simulated potato late blight epidemics within individual growing regions. A to $\mathbf{E}$, Spatial scenario sets 1 to 5, respectively (Table 3). Incidence is defined as the number of potato hectares infected (disease severity $\geq 1 \%$ ) relative to the number of potato hectares in the landscape. Circular data markers show predictions for the between field cultivar-mixing scheme and triangular data markers show predictions for the within-field cultivar-mixing scheme. Host connectivity $(q)$ is defined using equation A12. 
separation distance between the two regions increased, the frequency of favorable interregional dispersal conditions decreased and model outcomes became more sensitive to subtleties in weather conditions and randomness in landscape maps.

For incidence in the landscape as a whole (donor + receptor region), relative standard errors between years and within random landscape iterations were 6 to $13 \%$, with a mean value of $10 \%$. Relative standard errors between landscapes within years were 1 to $6 \%$, with a mean value of $2 \%$. This set of results was dominated by incidence in the donor region which, as the inoculated region, had the more severe epidemics. As a result, model outcomes for landscape incidence were less sensitive to weather conditions and variation in landscape maps compared with results for incidence in the receptor region only.

Together, these results indicate that substantial variability in model outcomes is generated both by the interplay between weather variability and randomness in landscape maps for the same design parameters. The noise in simulation outcomes does not obscure emergent patterns and the level of replication is deemed adequate, though greater precision could be reached by increasing the number of replications. This was not practically feasible. Importantly, the results indicate how the interplay between spatial landscape design and weather conditions can affect variability in disease spread at a landscape level.

Perturbation analysis. In both the one- and two-region scenarios, perturbation of the number of new lesions formed at each time step resulted in a significant change in the level of incidence, but no qualitative change in the response to the investigated variables (Figs. 5 and 6). One exception was manipulation of potato fraction under a minimizing perturbation (Fig. $5 \mathrm{~A}$, lower two curves). It can be seen that incidence can decrease with an increase in the amount of potato in the landscape. The absolute number of hectares infected actually increased for both cultivar mixing schemes (unpublished data) but, when incidence was expressed as a proportion of the (larger) number of hectares of potato in the landscape, the increase was masked. This was not an unexpected result, given the combination of a low proportion of host in the landscape and an artificial reduction in the number of new lesions that can form. Also, for the between-region mixing scheme in the two-region scenarios (Fig. 6C), under a minimizing perturbation, there was limited or no disease spread from the donor to the receptor region. Thus, emergent trends in simulation results were generally preserved even if processes were simulated with a substantial artificial error.

\section{DISCUSSION}

The results of this study indicate that landscape design can help to suppress the spread of $P$. infestans. The more effective of the strategies tested for individual growing regions of 6.4-by-6.4-km were those that decreased the susceptible fraction of host populations, decreased the amount of potato, or mixed susceptible and resistant cultivars at smaller spatial scales. Regional designs that focused on creating spatially isolated "islands" of potato cultivation separated by potato-free space (through manipulation of field size and clustering of potato fields) were found to increase epidemic severity. We found no evidence of thresholds in the response of epidemics to manipulation of spatial design variables. Effects of spatial design parameters on the prevalence of $P$. infestans were gradual.

The results of the two-region scenarios act to confirm the scant information in the literature on the large capacity of $P$. infestans for long-distance dispersal $(27,44,54)$. The use of space as an isolation barrier was effective in these scenarios, while the efficacy of this strategy was modulated by the spatial scale of mixing of potato cultivars. When growing regions were composed of fields that were planted with either a resistant or a susceptible cultivar, separation distances greater than those tested $(32 \mathrm{~km})$ were required to prevent the spread of disease from one region to another. In contrast, when the susceptible and resistant cultivars were mixed within fields, as cultivar mixtures, the minimum separation distance to completely prevent disease spread decreased to $32 \mathrm{~km}$. This result shows that there is an interaction between the spatial scale of cultivar mixing and between-region spread of disease; if potato cultivars are mixed at a finer spatial scale (within fields as opposed to between fields), then there are better opportunities for containing an invasion within a growing region by spatial separation. Nonetheless, geographic separation of growing regions according to potato cultivar was particularly successful in preventing between-region spread; a growing region composed entirely of a resistant cultivar could withstand the presence of a heavily sporulating region composed entirely of a susceptible cultivar at a distance of $\geq 16 \mathrm{~km}$. This is not an unexpected result; although large amounts of inoculum were generated by the susceptible region, the receiving resistant region was well protected by the level of host resistance therein. As landscape planners, however, we must consider the large-scale and long-term consequences of disease-buffering strategies. Geographic zonation according to potato cultivar type led to very heavy losses in the

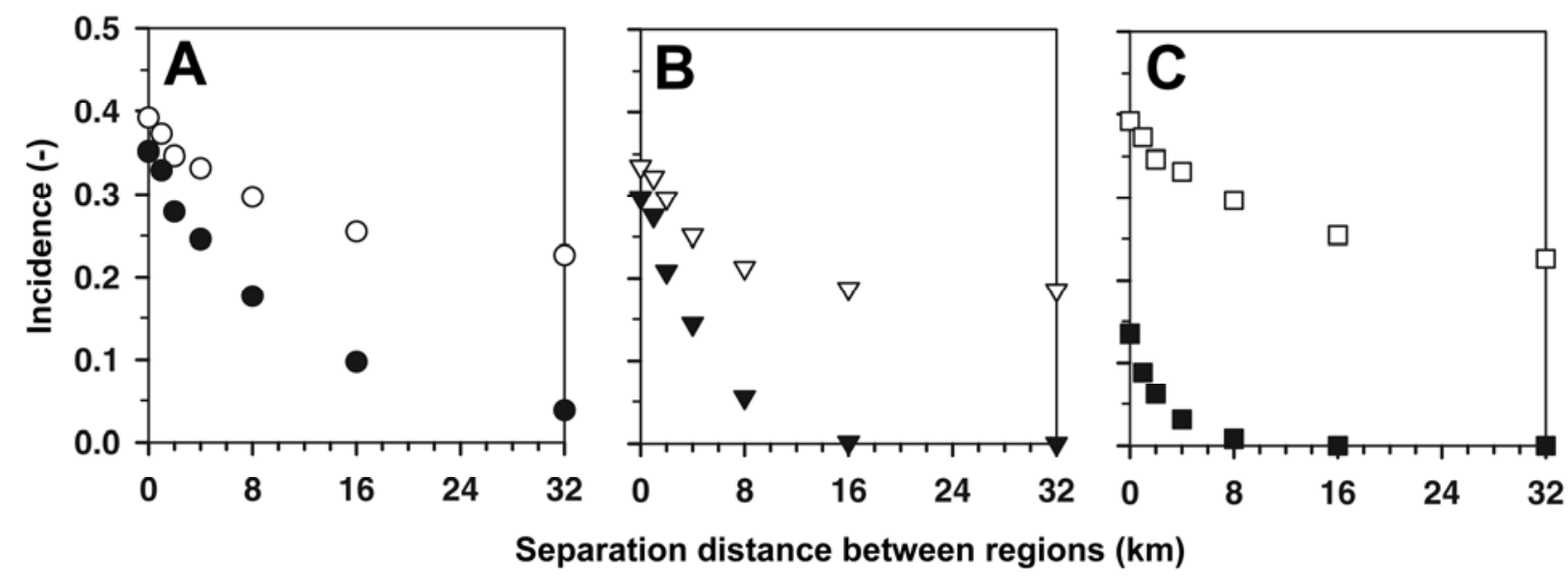

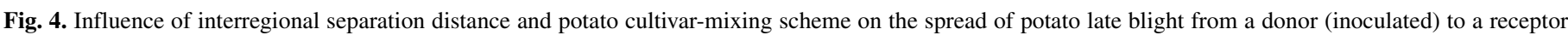

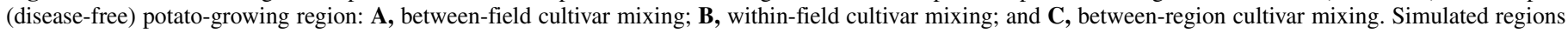

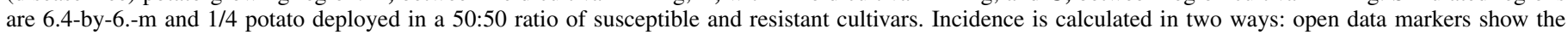

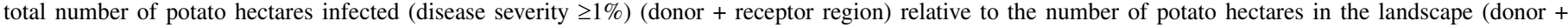

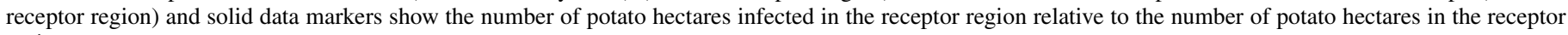
region. 
susceptible region and, thus, in the landscape as a whole. In addition, resistance genes will have less exposure to pathogen populations when deployed in a mixture as opposed to a monoculture (28). Overall, therefore, field-scale cultivar mixtures emerge as the best strategy for minimizing and containing disease within a region and for prolonging the durability of resistance genes.

Considerable variability in simulation outcomes resulted from variability in meteorological conditions. A large number of com-
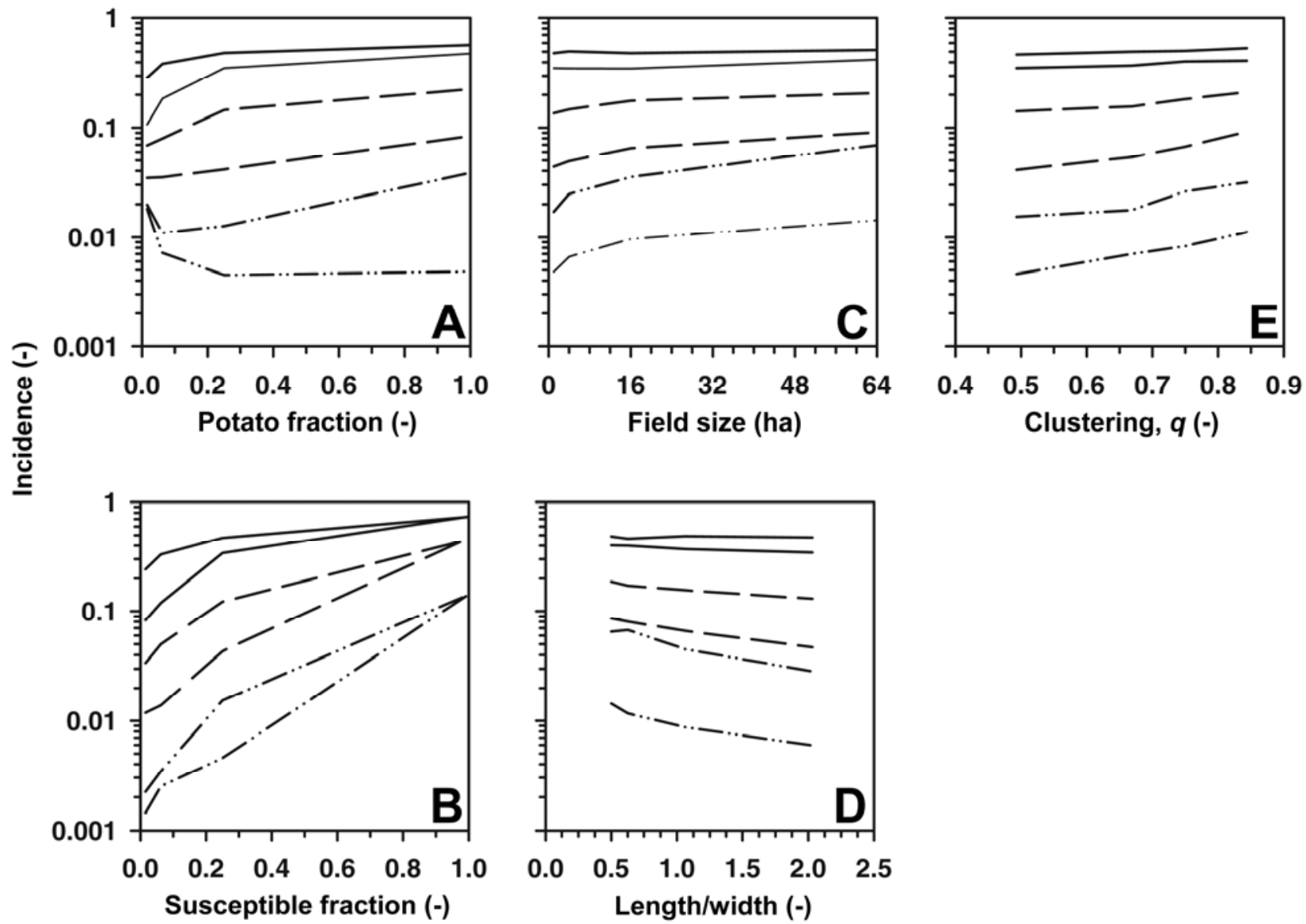

Fig. 5. Robustness of the one-region simulation results under an artificial magnifying or minimizing perturbation, whereby the number of new lesions formed in each grid cell at each time step is multiplied by a constant, $\rho$. A to E, Spatial scenario sets 1 to 5 , respectively (Table 3). Incidence is defined as the number of potato hectares infected (disease severity $\geq 1 \%$ ) relative to the number of potato hectares in the landscape. Panels show three paired sets of results, where the top curve in each pair shows predictions for the between-field cultivar-mixing scheme and the lower curve predictions for the within-field cultivar-mixing scheme. For each paired set of results, the value of $\rho$ is as follows: solid lines, $\rho=5$; dashed lines, $\rho=1$; and dashed-dotted lines, $\rho=0.2$. Host connectivity $(q)$ is defined using equation A12.

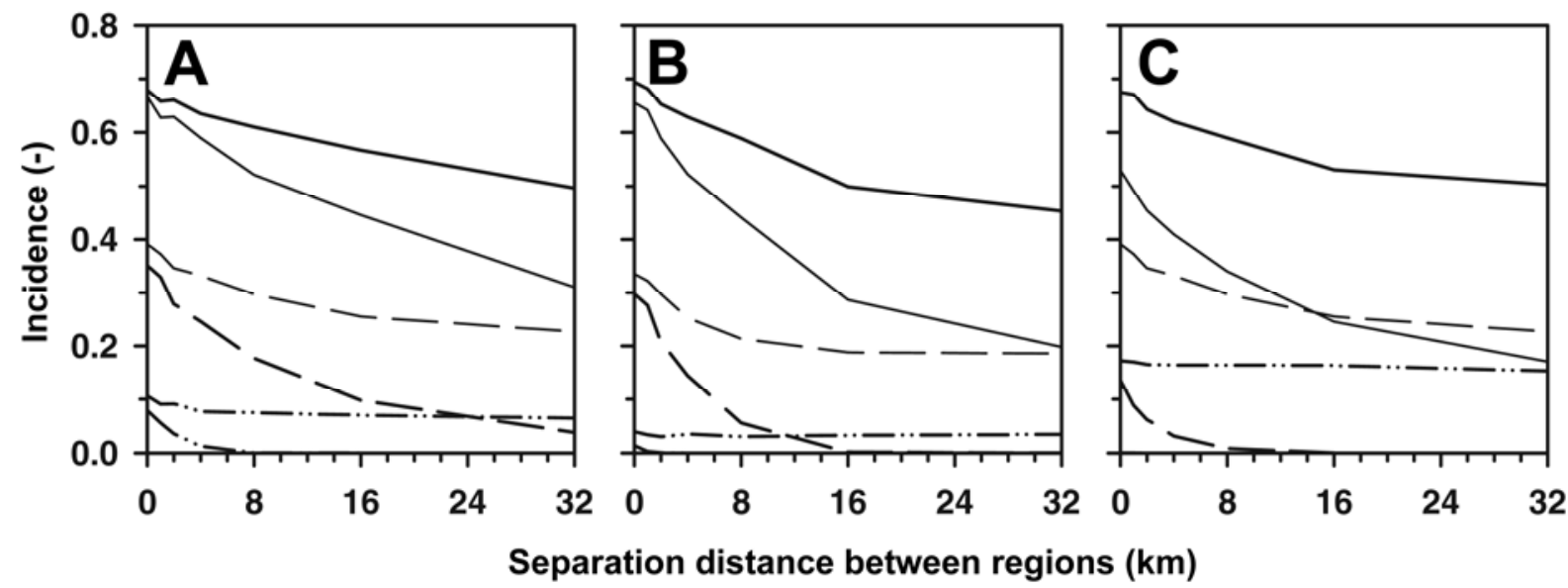

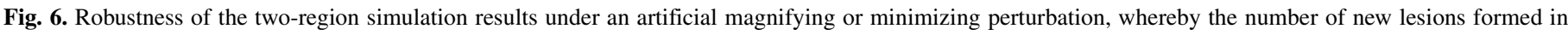

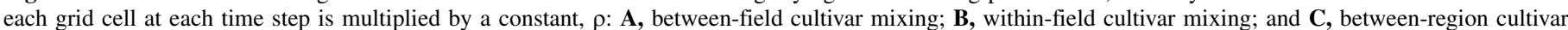

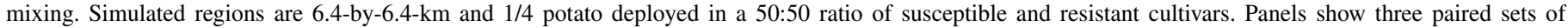

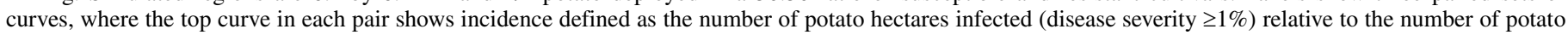

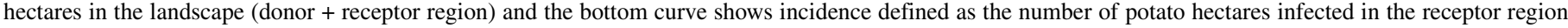

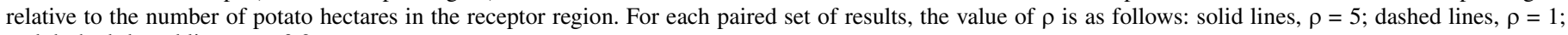
and dashed-dotted lines, $\rho=0.2$. 
binations of source and target locations and weather data were required to reduce noise and detect trends in model outcomes. Thus, it is the specific coincidence in time and space between weather conditions and the geographic locations of source and target sites that defines landscape connectivity and drives spatial epidemic expansion in a specific spatial context. In other words, under the same landscape design parameters, the rate of disease invasion may be very different from one year or spatial implementation to another, depending upon the vagaries of spore dispersal in relation to the placement of crop fields at the landscape level.

Deployment of resistant cultivars in cultivar mixtures was always more effective in reducing the severity of epidemics than deployment at greater spatial scales, regardless of the other spatial characteristics of the landscape. Although we are unaware of any other simulation studies or experiments that investigate mixture performance at a landscape scale, there are regional-scale realworld examples that serve to confirm this finding: 360,000 ha of mixtures were used to control powdery mildew on barley in the former German Democratic Republic in 1990 (50,52) and 230,000 ha of mixtures were used to control rice blast in China in $2002(24,28,36,51,55)$. The value of a fine-grain mixing strategy becomes more compelling given the apparent capacity of $P$. infestans for long-distance dispersal of viable inoculum. Other Oomycota are known to be capable of dispersal over large distances; for example, the disease front of pandemics of tobacco blue mold (causal agent Peronospora tabacina) in the United States have been observed to progress at a rate of up to $18 \mathrm{~km}$ day $^{-1}$ although this rapid advance may represent, in part, a seasonal phenological wave (3).

Simulations were also conducted with an "average dispersal kernel" ( $\bar{K}$ ) (see Appendix), in which all the daily kernels produced by the dispersion model (over the 10-year weather data set) were averaged and the resultant distribution normalized. The average kernel still reflected prevalence in weather conditions but was, overall, more radially symmetric than the daily kernels from which it was calculated (Figs. 7 and 8). With this kernel, as opposed to the daily kernels that are used in the present article, the invasion process was considerably faster, epidemics were more extensive, and the differences between landscape designs (in terms of disease suppression) were smaller (results not shown). This result, together with the results of the uncertainty analysis, suggest that time-averaged, radially symmetric dispersal functions may be too efficient in delivering inoculum to all available host sites at all times. However, this topic should be further explored and it was not included in the current article. We conclude that, in the simulation of airborne pathogen invasions, it is important to use an atmospheric dispersion model and large weather data sets that represent weather variability, and conduct many random landscape iterations.

A useful way to explain results of spatial resistance deployment strategies on disease spread is to interpret them in terms of the number of genotype units (a contiguous area containing a single host genotype; for example, a field or a cluster of fields) in the landscape, and the genotype unit area (ground area of a genotype unit) (31). The number of genotype units in the landscape affects pathogen invasion through its influence on the rate of disease spread between potato areas (e.g., a larger number of genotype units facilitates spread because they act as stepping stones). The more of such stepping stones there are, the closer they are and the more readily this distance is bridged by pathogen dispersal. Genotype unit area affects pathogen invasion through its influence on the rate of disease progress within potato areas (e.g., an increase in genotype unit area means that spores have, on average, further to travel before reaching the edge of an infected genotype unit

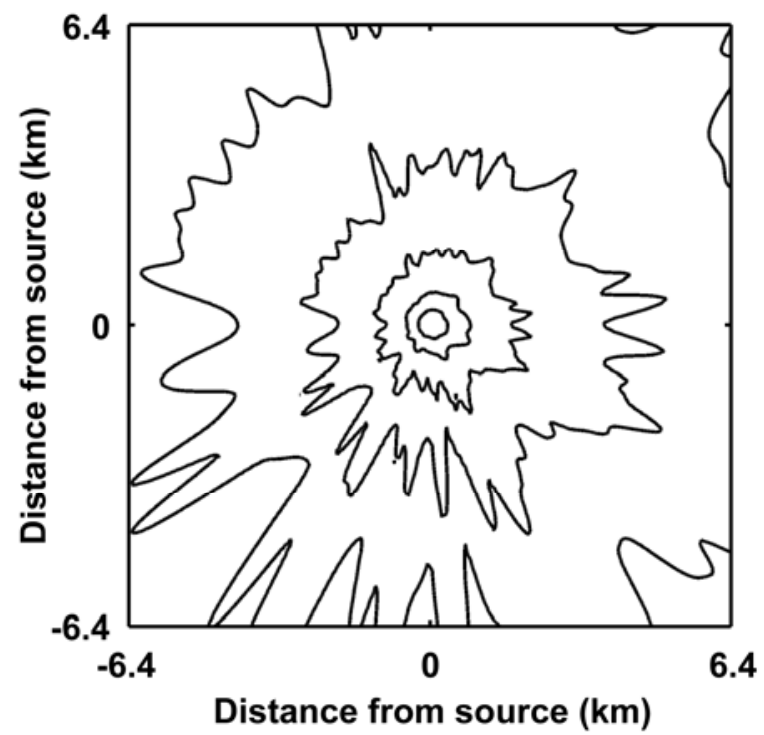

Fig. 8. Normalized dispersal kernel that is used to represent the average daily dispersal event over 10 growing seasons. This was calculated by accumulating hourly, viable spore deposition fluxes over 10 growing seasons, then dividing by the total mass under the kernel. Contours show the deposition flux of viable sporangia (no. $\mathrm{m}^{-2}$ ), ranging from $10^{-7}$ (inner contour) to $10^{-11}$ (outer contour), with an interval of factor 10 . The outer contour delineates an area containing $99.9 \%$ of the total deposition flux.

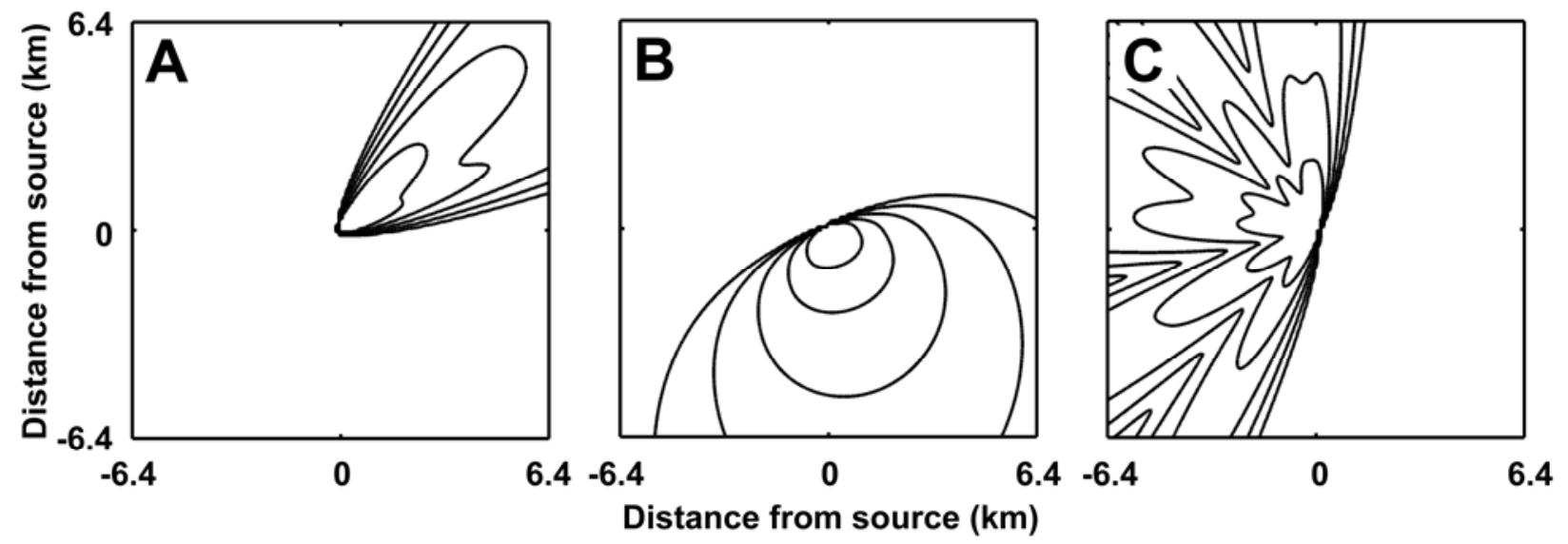

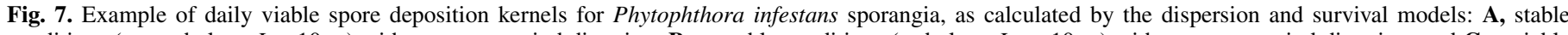

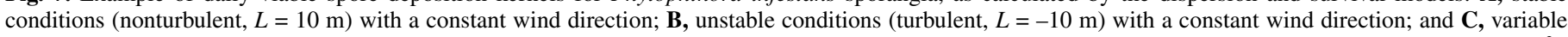

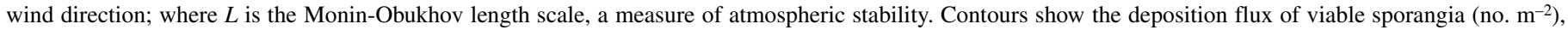

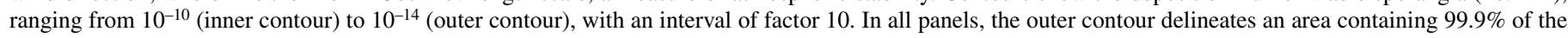
total deposition flux. 
and, therefore, are more likely to deposit within that genotype unit). A larger genotype unit area also increases the likelihood that spores from distant sources of inoculum will deposit (they make larger targets) and, when infected, larger sources of inoculum are produced. In other words: a large genotype unit area means a large catchment area of a single genotype, which can allow pathogens to spread very rapidly once they have colonized such a homogeneous area. In short: a larger number of genotype units facilitates invasion and a lower number impedes invasion; a larger genotype unit area facilitates invasion and a smaller genotype unit area impedes invasion. However, these principles do not elucidate quantitatively what is the best genotype pattern at a given density of hosts in the landscape. To answer this question, quantitative scenario studies with a process-based model, as conducted here, are needed.

Interestingly, the advantage to the pathogen of a larger genotype unit area can be offset by altering the shape of large genotype units (Fig. 3D). An increase in the length/width ratio of genotype units served to decrease incidence within a region. This result is also found in small-scale experiments (5). The proposed mechanism for this effect was a reduced spore interchange between potato plants, because spores were blown out of the strips as opposed to along the strips.

In combining this knowledge, we are confronted with a variety of options for the design of landscapes that suppress Phytophthora infestans invasions, which could be used individually or stacked. There are, however, a number of societal, strategic, and economic issues concerning the feasibility of implementation of these options, and these are summarized in Table 4. Nonetheless, significant reductions in the spread of $P$. infestans and other aerially spread pathogens can be obtained through careful spatial management of host resistance. The simulation framework presented here may be extended in the future through the inclusion of pathogen population genetics. This would enable the evaluation of spatial resistance deployment strategies in relation to pathogen evolutionary potential and durability of host resistance.

\section{APPENDIX}

Potato late blight model. The potato late blight model comprises five submodels: a model of the disease cycle in planta, models for spore release from sporangiophores and spore escape from the potato canopy, a model for host growth, and a model for fungicide management. The model for the disease cycle is described in full in Skelsey et al. (39-41), the host growth and fungicide management models in Skelsey et al. (40), and the models for spore release, escape, and survival in Skelsey et al. (38). A short description of these models is given below.

Disease cycle. The Phytophthora population in the model is age- and spatially structured and keeps track, for every grid cell in the landscape, of the number of lesions according to the day of establishment; thus, after $t$ days of simulation there will be $t$ age classes of lesions. Lesions are assumed to be circular and grow radially $\left(L G, \mathrm{~m} \mathrm{day}^{-1}\right)$, producing a new ring of growth (annulus) each day. New lesion annuli are latent for a period of time known as the latency period ( $L P$, days), after which they become infectious and produce spores. During each successive day, as another annulus of daily radial growth reaches the end of the latency period, this annulus will sporulate with intensity $\left(S I\right.$, no. $\left.\mathrm{m}^{-2}\right)$. The proportion of spores released from sporangiophores into the air at each time step is provided by the spore release submodel (described below). Crop density-dependent transmission (8) is accounted for through the effects of leaf area density on spore escape and spore deposition. The fraction of spores that escapes the canopy into the air above is provided by the spore escape submodel (described below). These spores are dispersed across the landscape by the long-range dispersion model (described below). Spores that do not escape the canopy autodeposit, and may contribute to epidemic development within the source cell. The percentage of spores (originating from within the grid cell and from neighboring grid cells) that deposit on the canopy is equivalent to the percentage of ground cover, which is calculated for potato canopies according to Haverkort and Harris (16). The remainder is deposited on the ground and is lost.

After sporulation (infectious period $[I P]$ lasting 1 day), infectious areas are classed as necrotic. Necrosis also occurs due to girdling of leaves and stems by lesions which, in the model, proceeds at a rate equal to the calculated rate of increase in latent area (47). Total latent, infectious, and necrotic lesion area in each grid cell is calculated by summing over age classes the number of lesions in each age class, multiplied by the age-specific area of

TABLE 4. Feasibility of spatial resistance deployment strategies for suppression of potato late blight invasions

Invasion suppression strategy

Decrease regional production

Increase diversification of resistance genes

Decrease field size

Elongate fields

Disaggregate production fields

Deploy cultivars in cultivar mixtures

Increase separation distances between growing regions
Feasibility of implementation

New production areas would be required

This would require significant institutional organization, and could increase production chain/infrastructure costs

Additional benefit of less potato in rotations

Consumers and market forces often dictate varietal choice

Genetic resistance resources are limited

Potential erosion of existing resistance resources is a concern

Genetic engineering could help address these concerns

This could increase production costs

Fields would need to be reorientated perpendicular to the prevailing wind direction

Efficacy depends on a prevailing wind direction

This could be implemented at farm level (i.e., via separation of groups of fields)

Plant-level mixing is problematic because different mixture components may require separation at harvest

Multiline cultivars (bred for phenotypic uniformity in agronomic traits) would facilitate plant-level mixing but, again, varietal choice is often dictated by consumers and market forces

Plant-level mixing could become a pragmatic option if existing cultivars can be engineered with different resistance genes (21)

Row-level mixing is an alternative mixing strategy for existing cultivars; this may require machinedesign for row-specific harvesting, which could increase production costs

Significant interregional separation distances are required

Elimination of pockets of potato production between regions would be required to eliminate stepping stones for disease

Concentration of potato production into dense, geographically isolated regions could increase the risk of yield loss due to primary sources of inoculum (e.g., infected seed potato or volunteer plants)

This would require significant institutional organization and could increase production chain/infrastructure costs 
latent, infectious, and necrotic tissue per lesion. Under the assumption that leaf lesion coverage and areas of girdled leaf tissue caused by $P$. infestans are distributed homogeneously over the canopy profile, shedding of leaves (decrease in leaf area index) affects all tissue types equally (i.e., shedding results in equal, proportional loss of healthy, latent, infectious, and necrotic areas). The age-structured population model for lesions is updated daily by aging the existing lesions by 1 day, and starting new lesions at a rate calculated as the product of the number of landed spores per square meter leaf area in a day, the infection efficiency (IE), and the fraction of area not yet occupied by colonies of $P$. infestans.

$I E, L G$, and $S I$ were measured in the laboratory on potato leaflets of two cultivars, providing parameter values for a susceptible and a resistant interaction (39). A complete listing of model parameters for simulation of different potato cultivars is given in Table 2. Latency and infectious periods are assumed to remain fixed regardless of the cultivar-isolate interaction, because the model is not sensitive to these parameters (39). The potato late blight model has previously been validated for these and other cultivar-isolate combinations by comparison of predicted epidemics with independent data from field trials (39).

The major difference between the current model version and the versions described in Skelsey et al. (39-41) is that the basic spatial unit for host and pathogen dynamics is 1 ha (100-by-100$\mathrm{m}$ grid cell). Therefore, dispersal of inoculum from plant to plant is not simulated. This is in contrast to previous model versions where the basic spatial unit was an individual plant and spread of disease through a crop was simulated with a mathematical (negative exponential) formula to describe the dispersal kernel. In this study, the spatial scale of interest lies beyond the plant level; rather, our primary interest is in movement of the pathogen between fields and regions, which motivated the choice of 1 ha as the basic spatial unit for host and pathogen dynamics. This also means that the areal expansion of lesions is affected by competition for available space at the scale of 1 ha whereas, in previous model versions, competition for space was at the single plant level. This means that simulated lesions can grow to be larger than the average true size of a leaflet. This is a justifiable assumption because potato late blight lesions can grow through petioles and stems to claim plant area exceeding a single leaflet. It was found that, after removal of the upper and lower $5 \%$ of lesion sizes, the trimmed mean simulated lesion size seldom exceeded two or three times the average true size of a leaflet. Powell et al. (35) showed that a maximum limit to lesion size does not sensitively affect epidemic growth rate.

Spore release. The fraction of spores that can be released, $f_{\mathrm{r}}$, every hour from sporangiophores is inversely related to humidity level <90\% (38):

$$
f_{\mathrm{r}}= \begin{cases}0 & R H \geq 90 \\ \frac{1}{R H-91}+1 & R H<90\end{cases}
$$

This relationship is assumed rather than derived from experimental fitting. It is based on the observation that most $P$. infestans sporangia are released at the first humidity drop in the early hours of the day (32) and an assumed $90 \%$ humidity criterion for leaf wetness. Spores that are not released within $24 \mathrm{~h}$ of formation are assumed to die off.

Spore escape. The fraction of released spores that can escape the canopy, $f_{\mathrm{e}}$, is dependent on wind speed, $u\left(\mathrm{~m} \mathrm{~s}^{-1}\right)$, and the leaf area index, $L A I$, of the canopy $(6,38-40)$ :

$$
f_{\mathrm{e}}=\exp \left(-L A I \sqrt{\frac{v_{\mathrm{d}}}{\kappa u}}\right)
$$

where $\kappa$ is the von Kármán constant, $u$ is the wind speed at a characteristic height within the canopy, and $v_{\mathrm{d}}\left(\mathrm{m} \mathrm{s}^{-1}\right)$ is the dry deposition velocity. Dry deposition velocity is estimated according to Ferrandino and Aylor (9) as:

$$
v_{\mathrm{d}}=(1+L A I) v_{\mathrm{s}}
$$

where $v_{\mathrm{s}}\left(\mathrm{m} \mathrm{s}^{-1}\right)$ is the settling velocity, given by Gregory (13) as $0.0085 \mathrm{~m} \mathrm{~s}^{-1}$ for $P$. infestans sporangia. Skelsey et al. (38) provides further details on the calculation of spore escape.

Environment-pathogen relations. A simplifying assumption is made that radial growth of $P$. infestans colonies continues within the leaf tissue and sporangia are produced, regardless of the weather; however, successful germination of dispersed sporangia is weather dependent. Two simple rules are used to analyze hourly weather data and determine if the conditions during the subsequent 24-h periods are suitable for sporangia to cause infection. The first rule determines whether the temperature and humidity each hour are suitable for the germination process to take place. The second rule determines whether the number of consecutive conducive hours required to allow germination to reach completion in a 24-h period is achieved. If the conditions of these rules are not met, then infection does not take place and the parameter $I E$ is set to 0 for that 24 -h period. Therefore, these rules act as a "switch," with new infection only occurring when conditions are conducive and not at all if they are not. Spores older than $24 \mathrm{~h}$ are no longer viable and cannot germinate. The 24-h periods run from 4:00 p.m. on each day till 4:00 p.m. the next day, ensuring that the cut-off between these intervals is made during the "dry" time of the day, when lack of leaf wetness hampers infection. These rules were described in detail by Skelsey et al. (39).

Host dynamics. The submodel for host dynamics was described in full by Skelsey et al. (40); therefore, only a summary is given here. Leaf area development is simulated through thermal time accumulation by computing the growing degree days as the positive difference between the (average daily) temperature and a base temperature $\left(2^{\circ} \mathrm{C}\right)$ below which leaf growth stops. $L A I$ is initialized at 0.05 , and increase in $L A I$ is modeled as a logistic function of growing degree days. $L A I$ is increased until the temperature sum reaches a maximum cultivar-specific value (estimated as 1,000 degree-days to correspond with a late-maturing cultivar), at which point net leaf growth becomes net leaf death. Shedding of leaves is also calculated as a logistic function of growing degree days. $L A I$ values are not spatially indexed (i.e., the same leaf area dynamics are used for each host cell in the landscape).

Fungicide management. Fungicide protection of potato crops is included in the modeling framework. Protectant sprays are applied once per week. A Weibull function is used to simulate the decay of protectant fungicides via their effect on the $I E$ of sporangia (40). Eradicant sprays are applied on an individual grid cell basis (100-by-100-m) when disease severity in that cell $\geq 1 \%$. For fields $>1$ ha, this is akin to applying an eradicant spray to a "hot spot" or focus of late blight within the field. Eradicant sprays kill $99 \%$ of lesions and also have protectant properties. Thus, when an eradicant spray is applied, a protectant spray is assumed and the weekly spray schedule for that individual cell is adjusted. Once an eradicant spray has been applied in an individual grid cell, they continue until the end of the growing season at a frequency of one spray every 14 days.

Dispersion model. The partial reflection Gaussian plume model of Overcamp (33) was used to compute spore transport and deposition because it is a fully analytical atmospheric dispersion model. Many applications of the Gaussian plume formula apply a mathematical device known as an "image source." The image source is used to satisfy a boundary condition of complete reflection of material at the surface (i.e., diffusion of material through the surface does not take place). The image source has the same strength as the real source and its location is the mirror image of the real source below the surface. This means that any portion of 
the plume that extends below the surface is instantaneously replaced (reflected) by the image source. In the model by Overcamp (33), the contribution from the image source is assigned a value equal to a fraction $\alpha$ of the strength of the real source, in order to account for removal of material from the lower part of the plume by dry deposition. This factor is known as the reflection coefficient. The reflection coefficient is not a constant; it is a function of the deposition velocity of spores and spread of the plume in the vertical direction, and it varies with downwind distance. It can be shown that Overcamp's solution satisfies an integral mass conservation equation specifying that the decrease in airborne flux equals the deposition (33). The basic formula (2) is:

$$
\bar{c}_{0}(x, y, 0)=\frac{Q\left[1+\alpha_{0}(x)\right]}{2 \pi \bar{u} \sigma_{\mathrm{y}} \sigma_{\mathrm{z}}} \exp \left(-\frac{y^{2}}{2 \sigma_{\mathrm{y}}^{2}}\right) \exp \left(-\frac{h^{2}}{2 \sigma_{\mathrm{z}}^{2}}\right)
$$

where $\bar{c}_{0}\left(\right.$ no. $\left.\mathrm{m}^{-3}\right)$ is the concentration of spores at the surface $(z=0 \mathrm{~m}) ; x(\mathrm{~m})$ and $y(\mathrm{~m})$ are coordinates in the downwind and crosswind directions, respectively; $Q$ (no. $\mathrm{s}^{-1}$ ) is the source emission strength; $\alpha_{0}(x)$ is the reflection coefficient for calculating ground level concentrations; $\bar{u}\left(\mathrm{~m} \mathrm{~s}^{-1}\right)$ is wind speed; $\sigma_{\mathrm{y}}(\mathrm{m})$ and $\sigma_{\mathrm{z}}(\mathrm{m})$ are the standard deviations of the concentration distribution in the crosswind and vertical directions, respectively; and $h$ (m) is the effective height of the source (canopy height minus the displacement height) (20). Arya (2) provides the following expression for the (partial) reflection coefficient:

$$
\alpha_{0}(x)=1-\frac{2 v_{\mathrm{d}}}{\left(v_{\mathrm{d}}+\frac{\bar{u} h}{\sigma_{\mathrm{z}}} \frac{d \sigma_{\mathrm{z}}}{d x}\right)}
$$

The dry deposition flux, $F_{\mathrm{d}}$ (no. $\mathrm{m}^{-2} \mathrm{~s}^{-1}$ ), at any point on the surface is given by:

$$
F_{\mathrm{d}}(x, y, 0)=v_{\mathrm{d}} \bar{c}_{0}(x, y, 0)
$$

The dispersion coefficients, $\sigma_{\mathrm{y}}$ and $\sigma_{\mathrm{z}}$, in equation A4 describe the shape of the plume in the crosswind and vertical directions. They are functions of downwind distance from the source and atmospheric turbulence (i.e., as downwind distance increases, turbulent eddies of air cause the plume to expand outward and upward and $\sigma_{\mathrm{y}}$ and $\sigma_{\mathrm{z}}$ increase). These coefficients were parameterized using the Taylor (45) model, which is widely regarded as giving the best estimation of $\sigma_{\mathrm{y}}$ and $\sigma_{\mathrm{y}}(2)$ :

$$
\begin{gathered}
\sigma_{\mathrm{y}}=\sigma_{\mathrm{v}} t f_{\mathrm{y}}\left(\tau / T_{\mathrm{L}}\right) \\
\sigma_{\mathrm{z}}=\sigma_{\mathrm{w}} t f_{\mathrm{z}}\left(\tau / T_{\mathrm{L}}\right)
\end{gathered}
$$

with empirical formulations proposed by Draxler (7):

$$
\begin{aligned}
& 1 / f_{\mathrm{y}}= \begin{cases}1+0.9(\tau / 300)^{0.5} & L<0 \\
1+28 / \tau^{0.5} & L>0\end{cases} \\
& 1 / f_{\mathrm{z}}= \begin{cases}1+0.9(\tau / 500)^{0.5} & L<0 \\
1+0.9(\tau / 50)^{0.5} & L>0\end{cases}
\end{aligned}
$$

where $\sigma_{\mathrm{v}}$ and $\sigma_{\mathrm{w}}\left(\mathrm{m} \mathrm{s}^{-1}\right)$ are the standard deviations of wind velocity fluctuation (turbulence intensities) in the horizontal and vertical directions; $\tau$ (s) is the travel time $(\tau=x / \bar{u}) ; T_{\mathrm{L}}(\mathrm{s})$ is the Lagrangian time scale, which represents the characteristic time scale of turbulent eddies of air; and $L(\mathrm{~m})$ is the Monin-Obukhov length scale, calculated using Monin-Obukhov similarity theory via the "profile method" $(37,43)$. Formulae for the turbulence intensities, $\sigma_{v}$ and $\sigma_{w}$, are given by Arya (2).
Spore survival. The experimental results of Mizubuti et al. (27) are used to determine the fraction of released spores that remain infective during transport. The fraction of spores that remain viable after transportation, $f_{\mathrm{v}}$, is dependent on the dose, $\varphi\left(\mathrm{MJ} \mathrm{m}^{-2}\right)$, of global radiation received (direct plus diffuse shortwave radiation) during transport:

$$
f_{\mathrm{v}}=0.79 \exp (-1.21 \varphi)
$$

where $\varphi$ is the product of the travel time (time spent in the air before deposition), $\tau(\mathrm{s})$, and the flux of incoming global radiation, $G R\left(\mathrm{~W} \mathrm{~m}^{-2}\right)$. According to the results of Mizubuti et al. (27), a 1-h exposure on a sunny day was enough to inactivate $95 \%$ of the sporangia of a $P$. infestans isolate belonging to the US-1 clonal lineage.

Solution of dispersal phenomena. Spatial dispersal processes are accounted for by daily convolutions between a "dispersal kernel" and the spatial distribution of inoculum escape (equations A1 to A3) at sources. The dispersal kernels describe the probability of viable spores landing at a particular distance from a source, in two-dimensional space. The dispersal kernels, or viable spore deposition footprints, are calculated by the dispersion component and are spatially invariant (i.e., the same dispersal kernel is applied to each potato grid cell in the landscape).

Although the overall model operates at a 1-day time-step and a 100-by-100-m grid cell resolution, spore dispersal is first calculated at an hourly basis and 10-by-10-m resolution, to account for weather variability (notably wind direction) within a day and potentially steep spatial dispersal gradients. Furthermore, the Gaussian plume model cannot be used to calculate dispersal within a source cell; it can only calculate dispersal to other cells in the spatial grid. Therefore, the $10-$ by-10-m resolution enables the model to account for a potential dominance of autoinfection (infection caused by inoculum produced on the same host unit) over migration of inoculum from other host locations, which is particularly important for a realistic representation of the spatiotemporal spread of disease (29). Ten hourly spore dispersal kernels (see below) are calculated, added, and subsequently aggregated to the appropriate grid cell resolution to obtain the daily dispersal kernel at landscape level. This works as follows.

For each hour of meteorological input data, a 10-by-10-m grid of coordinates is defined that spans the extent of the landscape in both positive and negative $x$ and $y$ directions. A rotation of the axes is performed to align the $x$ axis with the downwind direction for that hour. A single source is located at the center of the grid, and dispersal is simulated using weather data from 7:00 a.m. until 4:00 p.m., because release and dispersal of spores of $P$. infestans is assumed to be most likely during these hours (32). A total of 1 spore is released from the center of the grid over the course of each day; therefore, 0.1 spores are released each hour (7:00 a.m. until 4:00 p.m. inclusive). Equations A4 to A9 are used as described above to produce a two-dimensional distribution of viable spore deposition flux values (no. $\mathrm{m}^{-2}$ ) for that hour. Hourly distributions are added together over the course of the 10-h dispersal period, and the final daily distribution is aggregated spatially from a 10-by-10-m grid to match the grid resolution of other model components. This is the daily dispersal kernel, $K$ (no. $\mathrm{m}^{-2}$ ), or viable spore deposition footprint. Some example kernels are given in Figure 7. The ability of these kernels to deliver viable spores to receiver sites depends on many factors, such as wind direction, variability in wind direction, wind speed, solar irradiation, and atmospheric turbulence. Example kernels in Figure 7 clearly illustrate the variability of the daily kernels and, thus, the utility of an atmospheric dispersion model in capturing the effects of vagaries in weather conditions on inoculum dispersal.

Convolutions are implemented at a daily time step in the model via fast Fourier transforms (22). This solution method requires periodic boundary conditions, resulting in "wrap-around" effects, 
whereby any spore dispersing outside the boundaries of the landscape will "reappear" on the opposite edge of the landscape when spatial distributions are back-transformed into the spatial domain. In this study, spatial distributions are padded with a large border of nonhost space prior to convolution ("zero-padding"). Spores that are redistributed by the kernel into the nonhost space are removed from the system, thereby preventing wrap-around effects. Thus, the simulations represent a potato landscape surrounded by space without potato plants.

Host connectivity. This parameter makes use of a dispersal kernel, calculated as described above in the "Solution of dispersal phenomena" section. Days conducive to disease development were selected (see "Environment-pathogen relations" section) from the 10-year weather data set, and only hours between 7:00 a.m. and 4:00 p.m. were used as input, because these were assumed to be the hours when spore dispersal was most likely. The resultant, cumulative distribution of viable spore deposition flux values was normalized by division with the total mass under the kernel to provide an average viable spore deposition kernel for the entire period of interest (10 growing seasons), $\bar{K}$ (no. $\mathrm{m}^{-2}$ ) (Fig. 8). This is an alternative and more realistic approach to using a radially symmetric statistical distribution for landscape-scale dispersal. It can be seen that $\bar{K}$ is not radially symmetric (Fig. 8); therefore, such an approach can be used to produce dispersal kernels that reflect prevalence in weather conditions for any area and time span, and also extreme weather events.

The host connectivity parameter, $q$, expresses the overall probability that a propagule produced in a host field, when dispersed according to $\bar{K}$, will be deposited within (upon) a host field (whether the same field or another field) (41). In order to derive $q$, a spatial convolution is used to redistribute spores from each source location in the landscape to each target location. Let $\mathrm{s}(x, y)$ express a density of spores (per unit ground area) at grid location $(x, y) ; \mathrm{s}(x, y)$ is $1 \mathrm{~m}^{-2}$ if the grid cell is a potato field and $0 \mathrm{~m}^{-2}$ otherwise. Let $\left(x^{\prime}, y^{\prime}\right)$ denote source locations, and $(x, y)$ target locations. Then we can write:

$$
s(x, y)=\int_{x^{\prime} y^{\prime}} s\left(x^{\prime}, y^{\prime}\right) \bar{K}\left(x-x^{\prime}, y-y^{\prime}\right) d y^{\prime} d x^{\prime}
$$

where $\bar{K}\left(x-x^{\prime}, y-y^{\prime}\right)$ is the average dispersal kernel described above. The density of spores redistributed to each new location, $s(x, y)$ is then weighted with a Heaviside function, $H$, which is 1 if the target location contains host tissue and 0 otherwise (i.e., the Heaviside function is used to facilitate calculation of successful spore deposition in heterogeneous landscapes). Integration over the whole spatial domain then gives the gives the total number of successfully redistributed spores, $s$ (no.), in the landscape:

$$
s=\iint_{x} H(s(x, y)) \iint_{x^{\prime} y^{\prime}} s\left(x^{\prime}, y^{\prime}\right) \bar{K}\left(x-x^{\prime}, y-y^{\prime}\right) d y^{\prime} d x^{\prime} d y d x
$$

To obtain the overall probability, $q$, that a spore produced somewhere in the landscape will land on a host tissue, equation A11 is divided by the total number of spores produced in the landscape:

$$
q=\frac{\iint_{x y} H(s(x, y)) \iint_{x^{\prime} y^{\prime}} s\left(x^{\prime}, y^{\prime}\right) \bar{K}\left(x-x^{\prime}, y-y^{\prime}\right) d y^{\prime} d x^{\prime} d y d x}{\iint_{x^{\prime} y^{\prime}} s\left(x^{\prime}, y^{\prime}\right) d y^{\prime} d x^{\prime}}
$$

Parameter $q$ describes connectivity from a physical dispersal and topographical perspective, through quantification of the scale of dispersal processes and the scale of heterogeneities in the landscape. It is a probability and cannot be $<0$ or $>1$. Parameter $q$ is used to provide a measure of clustering of potato populations and is used in landscape generation (as described in the text).
Validation of dispersion model. The ability of the partial reflection model to predict spore plumes is tested by calculating expected spore concentrations and assessing goodness of fit with the experimental spore dispersal data of Spijkerboer et al. (42). These experiments were carried out in a 200-by-200-m field of potato in Wageningen (latitude $51^{\circ} 58^{\prime} \mathrm{N}$, longitude $5^{\circ} 40^{\prime} \mathrm{E}$ ), the Netherlands, in summer 1997. Aerial spore concentrations were measured using spore traps at distances of $\leq 100 \mathrm{~m}$ from a point source of Lycopodium clavatum spores. Data from a total of 15 measurement sessions are used here. The partial reflection model of Overcamp (33) as given above is used to calculate ground level concentrations, whereas these experimental data were measured at various heights above the surface. In order to make the partial reflection model height dependent, the basic equations must be reformulated. The concentration, $\bar{c}$ (no. $\mathrm{m}^{-3}$ ), at receptor point $(x, y, z)$ has a contribution from the image source via a streamline that cuts through the ground plane at distance $x_{\mathrm{G}}(\mathrm{m})$ :

$$
\begin{gathered}
\bar{c}(x, y, z)=\frac{Q\left[1+\alpha_{0}\left(x_{\mathrm{G}}\right)\right]}{2 \pi \bar{u} \sigma_{\mathrm{y}} \sigma_{\mathrm{z}}} \exp \left(-\frac{y^{2}}{2 \sigma_{\mathrm{y}}^{2}}\right) \\
\left\{\exp \left[-\frac{(z-h)^{2}}{2 \sigma_{\mathrm{z}}^{2}}\right]+\exp \left[-\frac{(z+h)^{2}}{2 \sigma_{\mathrm{z}}^{2}}\right]\right\}
\end{gathered}
$$

with $\alpha_{0}\left(x_{\mathrm{G}}\right)$ given by:

$$
\alpha_{0}\left(x_{\mathrm{G}}\right)=1-\frac{2 v_{\mathrm{d}}}{\left(v_{\mathrm{d}}+\frac{\bar{u} h}{\sigma_{\mathrm{z}}} \frac{d \sigma_{\mathrm{z}}\left(x_{\mathrm{G}}\right)}{d x}\right)}
$$

An implicit equation for $x_{\mathrm{G}}$ is (33):

$$
z+h=h \frac{\sigma_{\mathrm{z}}(x)}{\sigma_{\mathrm{z}}\left(x_{\mathrm{G}}\right)}
$$

Model performance was evaluated using Willmott's (49) modified index of agreement, $D$ :

$$
D=1-\left[\sum_{i=1}^{N}\left|P_{i}-O_{i}\right| / \sum_{i=1}^{N}\left(\left|P_{i}^{\prime}\right|+\left|O_{i}{ }^{\prime}\right|\right)\right] \quad 0 \leq D \leq 1
$$

where $P=$ prediction, $O=$ observation, $P_{i}{ }^{\prime}=P_{i}-\bar{O}$ and $O_{i}{ }^{\prime}=$ $O_{i}-\bar{O}$. The value of $D$ is a measure of how well the observed

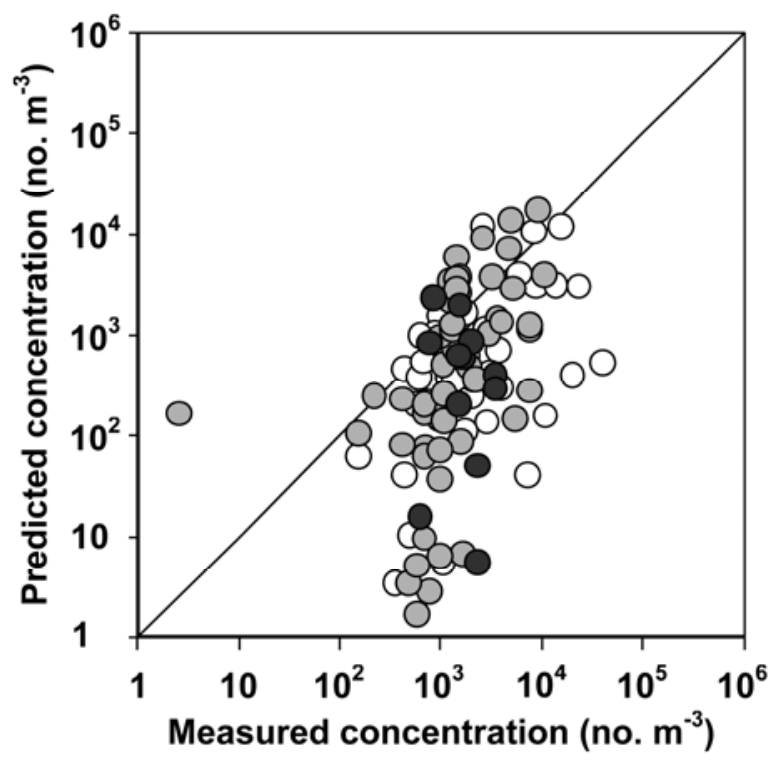

Fig. 9. Predicted versus measured spore concentrations: white circle $=25<$ distance from source $\leq 50 \mathrm{~m}$, light-gray circle $=50<$ distance from source $\leq 75 \mathrm{~m}$, and dark-gray circle $=$ distance from source $>75 \mathrm{~m}$. The solid line represents a 1:1 line. 
deviations about the observed mean value match the predicted deviations about the same observed mean value. A value of 1 denotes perfect correspondence between predictions and observations.

A log-log plot of predicted versus measured spore concentrations reveals that the model had a tendency to underpredict observed aerial spore concentrations (Fig. 9). As an overall measure of predictive accuracy, a score of 0.6 was achieved for the relative and bounded measure, $D$. This is considered to be a satisfactory result for a fully analytical dispersal and deposition model.

\section{ACKNOWLEDGMENTS}

Funding for this study was provided by the Dutch Ministry of Agriculture, Nature Management and Fisheries through the DuRPh project theme "Resistance management," project no. 3340043100; the Umbrella Plan Phytophthora (DWK 427); and the EU Network of Excellence ENDURE, EU Project number 031499.

\section{LITERATURE CITED}

1. Andrivon, D., Lucas, J. M., and Ellisseche, D. 2003. Development of natural late blight epidemics in pure and mixed plots of potato cultivars with different levels of partial resistance. Plant Pathol. 52:586-594.

2. Arya, S. P. 1999. Air Pollution Meteorology and Dispersion. Oxford University Press, New York.

3. Aylor, D. E. 2003. Spread of plant disease on a continental scale: role of aerial dispersal of pathogens. Ecology 84:1989-1997.

4. Birch P. R. J., and Whisson, S. C. 2001. Phytophthora infestans enters the genomic era. Mol. Plant Pathol. 2:257-63.

5. Bouws, H., and Finckh, M. R. 2008. Effects of strip intercropping of potatoes with non-hosts on late blight severity and tuber yield in organic production. Plant Pathol. 57:916-927.

6. de Jong, M., Bourdôt, G. W., Powell, J., and Goudriaan, J. 2002. A model of the escape of Sclerotinia sclerotiorum ascospores from pasture. Ecol. Model. 150:83-105.

7. Draxler, R. R. 1976. Determination of atmospheric diffusion parameters. Atmos. Environ. 10:99-105.

8. Ferrandino, F. J. 2008. Effect of crop growth and canopy filtration on the dynamics of plant disease epidemics spread by aerially dispersed spores. Phytopathology 98:492-503.

9. Ferrandino, F. J., and Aylor, D. E. 1985. An explicit equation for deposition velocity. Bound. Layer Meteorol. 31:197-201.

10. Forbes, G. 2004. Global overview of late blight. Pages 3-10 in: Proc. Regional Workshop Potato Late Blight East and Southeast Asia and the Pacific. C. Lizarraga, ed. Yezin, Myanmar.

11. Fry, W. 2008. Phytophthora infestans: the plant (and $R$ gene) destroyer. Mol. Plant Pathol. 9:385-402.

12. Garrett, K. A., and Mundt, C. C. 2000. Host diversity can reduce potato late blight severity for focal and general patterns of primary inoculum. Phytopathology 90:1307-1312.

13. Gregory, P. H. 1973. The Microbiology of the Atmosphere. Wiley, New York.

14. Haas, B. J., Kamou, S., Zody, M. C., Jiang, R. H. Y., and Handsaker, R. E. et al. 2009. Genome sequence and analysis of the Irish potato famine pathogen Phytophthora infestans. Nature 461:393-398.

15. Haverkort, A. J., Boonekamp, P. M., Hutten, R., Jacobsen, E., Lotz, L. A. P., Kessel, G. J. T., Visser, R. G. F., and van der Vossen, E. A. G. 2008. Societal costs of late blight in potato and prospects of durable resistance through cisgenic modification. Potato Res. 51:47-57.

16. Haverkort, A. J., and Harris, P. M. 1987. A model for potato growth and yield under tropical highland conditions. Agric. For. Meteorol. 39:271282.

17. Hijmans, R. J., Forbes, G. A., and Walker, T. S. 2000. Estimating the global severity of potato late blight with GIS-linked disease forecast models. Plant. Pathol. 49:697-705.

18. Hirst, J. M. 1953. Changes in atmospheric spore content: diurnal periodicity and the effects of weather. Trans. Br. Mycol. Soc. 36:375-393.

19. Hyre, R. A. 1950. Spore traps as an aid in forecasting several downy mildew type diseases. Plant Dis. Rep. (Suppl.) 190:14-18.

20. Jacobs, A. F. G., and Boxel, J. H. 1991. Horizontal and vertical distribution of wind speed in a vegetation canopy. Neth. J. Agric. Sci. 39:165-178.

21. Kessel, G. J. T., Boonekamp, P. M., and Haverkort, A. J. 2007. Potato late blight in the Netherlands, a thing of the past? New frontiers in resistance breeding and disease. Page 15 in: Proc. EAPR Pathol. Sect. Semin. New and old pathogens of potato in changing climate. A. Hannukkala and M. Segerstedt, eds. Hatula, Finland.

22. Kot, M., Lewis, M. A., and van den Driessche, P. 1996. Dispersal data and the spread of invading organisms. Ecology 77:2027-2042.

23. Large, E. C. 1940. The Advance of the Fungi. Jonathan Cape, London.

24. Leung, H., Zhu, Y., Revilla-Molina, I., Fan, J. X., Chen, H., Pangga, I., Vera Cruz, C., and Mew, T. W. 2003. Using genetic diversity to achieve sustainable rice disease management. Plant Dis. 87:1156-1169.

25. Madden, L. V., Hughes, G., and van den Bosch, F. 2007. The Study of Plant Disease Epidemics. The American Phytopathological Society, St. Paul, MN.

26. McDonald, B. A., and Linde, C. 2002. Pathogen population genetics, evolutionary potential, and durable resistance. Annu. Rev. Phytopathol. 40:349-379.

27. Mizubuti, E. S. G., Aylor, D. E., and Fry, W. E. 2000. Survival of Phytophthora infestans sporangia exposed to solar radiation. Phytopathology 90:78-84.

28. Mundt, C. C. 2002. Use of multiline cultivars and cultivar mixtures for disease management. Annu. Rev. Phytopathol. 40:381-410.

29. Mundt, C. C. 2009. Importance of autoinfection to the epidemiology of polycyclic foliar disease. Phytopathology 99:1116-1120.

30. Mundt, C. C. 2009. Long-distance dispersal and accelerating waves of disease: empirical relationships. Am. Nat. 173:456-466.

31. Mundt, C. C., and Browning, J. A. 1985. Development of crown rust epidemics in genetically diverse oat populations: effect of genotype unit area. Phytopathology 75:607-610.

32. Nielsen, B. J., Hansen, J. G., Pinnschmidt, H., Narstad, R., Hermansen, A., Le, V. H., and Hannukkala, A. 2007. Studies of release and infectivity of Phytophthora infestans sporangia under field conditions. Pages 211220 in: Proc. Tenth Workshop Eur. Network Dev. Integrated Control Strategy of Potato Late Blight. H. T. A. M. Schepers, ed. Bologna, Italy.

33. Overcamp, T. J. 1976. A general Gaussian diffusion-deposition model for elevated point sources. J. Appl. Meteorol. 15:1167-1171.

34. Philips, S. L., Shaw, M. W., and Wolfe, M. S. 2005. The effect of potato variety mixtures on epidemics of late blight in relation to plot size and level of resistance. Ann. Appl. Biol. 147:245-252.

35. Powell, J. A., Slapnicar, I., and van der Werf, W. 2005. Epidemic spread of a lesion-forming plant pathogen-analysis of a mechanistic model with infinite age structure. Linear Algebra Appl. 398:117-140.

36. Revilla-Molina, I. M., Bastiaans, L., Van-Keulen, H., Kropff, M. J., Hui, F., and Castilla, N. P. 2009. Does resource complementarity or prevention of lodging contribute to the increased productivity of rice varietal mixtures in Yunnan, China? Field Crops Res. 111:303-307.

37. Skelsey, P., Holtslag, A. A. M., and van der Werf, W. 2008. Development and validation of a quasi-Gaussian plume model for the transport of botanical spores. Agric. For. Meteorol. 148:1383-1494.

38. Skelsey, P., Kessel, G. J. T., Holtslag, A. A., Moene, A. F., and van der Werf, W. 2009. Regional spore dispersal as a factor in disease risk warnings for potato late blight: a proof of concept. Agric. For. Meteorol. 149:419-430.

39. Skelsey, P., Kessel, G. J. T., Rossing, W. A. H., and van der Werf, W. 2009. Parameterization and evaluation of a spatiotemporal model of the late blight pathosystem. Phytopathology 99:290-300.

40. Skelsey, P., Kessel, G. J. T., Rossing, W. A. H., and van der Werf, W. 2009. Scenario approach for assessing the utility of dispersal information in decision support for aerially spread plant pathogens, applied to Phytophthora infestans. Phytopathology 99:887-895.

41. Skelsey, P., Rossing, W. A. H., Kessel, G. J. T., Powell, J., and van der Werf, W. 2005. Influence of host diversity on development of epidemics: an evaluation and elaboration of mixture theory. Phytopathology 95:328338.

42. Spijkerboer, H. P., Beniers J. E., Jaspers, D., Schouten, H. J., Goudriaan, J., Rabbinge, R., and van der Werf, W. 2002. Ability of the Gaussian plume model to predict and describe spore dispersal over a potato crop. Ecol. Model. 155:1-18.

43. Stull, R. B. 1988. An Introduction to Boundary Layer Meteorology. Kluwer Academic Publishers, Dordrecht, The Netherlands.

44. Sunseri, M. A., Johnson, D. A., and Dasgupta, N. 2002. Survival of detached sporangia of Phytophthora infestans exposed to ambient, relatively dry atmospheric conditions. Am. J. Potato Res. 79:443-450.

45. Taylor, G. I. 1921. Diffusion by continuous movements. Proc. Lond. Math. Soc. 20:196-211.

46. van der Zaag, D. E. 1956. Overwintering en epidemiologie van Phytophthora infestans, tevens enige nieuwe bestrijdingsmogelijkheden. Ph.D. thesis, Landbouwhogeschool, Wageningen, The Netherlands.

47. van Oijen, M. 1992. Selection and use of a mathematical model to evaluate components of resistance to Phytophthora infestans in potato. Eur. J. Plant Pathol. 98:192-202.

48. Walker, T. S, Schmiediche, P. E, and Hijmans, R. J. 1999. World trends and patterns in the potato crop: An economic and geographic survey. 
Potato Res. 42:241-364.

49. Willmott, C. J., Ackleson, S. G., Davis, R. E., Feddema, J. J., Klink, K. M., Legates, D. R., O’Donnell, J., and Rowe, C. M. 1985. Statistics for the evaluation and comparison of models. J. Geophys. Res. 90:8995-9005.

50. Wolfe, M. S. 1992. Maintaining the value of our varieties. Pages 1055-67 in: Barley Genetics VI, Vol. 2. L. Munk, ed. Munksgaard Int. Publ., Copenhagen.

51. Wolfe, M. S. 2000. Crop strength through diversity. Nature 406:681-682.

52. Wolfe, M. S, Brändle, U., Koller, B., Limpert, E., McDermott, J. M.,
Müller, K., and Schaffner, D. 1992. Barley mildew in Europe: population biology and host resistance. Euphytica 63:125-39.

53. Zadoks, J. C. 2008. On the Political Economy of Plant Diseases. Wageningen Academic Publishers, Wageningen, The Netherlands.

54. Zwankhuizen, M. J., Govers, F., and Zadoks, J. C. 1998. Development of potato late blight epidemics: disease foci, disease gradients, and infection sources. Phytopathology 88:754-763.

55. Zhu, Y. Y., Chen, H., Fan J. H., Wang, Y. Y., and Li Y. 2000. Genetic diversity and disease control in rice. Nature 406:718-722. 